\title{
EARLY CHILDHOOD EDUCATORS' PERCEPTION OF THEIR TRAINING AND SUPPORT NEEDS FOR INCLUSIVE EDUCATION
}

\author{
by \\ Evelina Siwik \\ Diploma with honours in Early Childhood Education, George Brown College, Toronto, 2012 \\ Honours Bachelor of Arts in Psychology, York University, Toronto, 2010
}

\author{
A Major Research Paper \\ Presented to Ryerson University
}

in partial fulfillment of the requirements for the degree of

\author{
Master of Arts \\ in the Program of \\ Early Childhood Studies
}

Toronto, Ontario, Canada, 2013

(C) Evelina Siwik 2013 


\section{Author's Declaration}

I hereby declare that I am the sole author of this major research project. This is a true copy of the major research project, including any required final revisions.

I authorize Ryerson University to lend this major research project to other institutions or individuals for the purpose of scholarly research.

I further authorize Ryerson University to reproduce this major research project by photocopying or by other means, in total or in part, at the request of other institutions or individuals for the purpose of scholarly research.

I understand that my major research project may be made electronically available to the public. 


\title{
EARLY CHILDHOOD EDUCATORS' PERCEPTION OF THEIR TRAINING AND SUPPORT NEEDS FOR INCLUSIVE EDUCATION
}

\author{
(C) Evelina Siwik 2013 \\ Master of Arts \\ Early Childhood Studies \\ Ryerson University
}

\begin{abstract}
Inclusion literature is multifaceted; demonstrated by variation in meaning and interpretation of the concept. Within the body of literature on inclusion, educators' perceive training and support needs as key barriers to practicing inclusive education. The current study explores the perceptions of twenty early childhood educators across Toronto, Ontario about their own training and support needs for enacting inclusive education. A qualitative interview method, and triangulation with two questionnaires were used to collect data. The social model of disability was the theoretical framework that guided the research project. Major themes came from the topics identified in the literature and elicited through interview questions. Several subthemes also emerged during data analysis. Results of the thematic analysis suggest that opportunities for ongoing training and more access to resources are sought by educators and might increase confidence in their ability to include children with disabilities in their programs. Recommendations for future research and practice are discussed.
\end{abstract}

Key Words: Inclusion, perceptions, beliefs, early childhood educators, managers, individual program plan, social model of disability, training needs, support needs 


\section{Acknowledgements}

Cristian Lukaszyk: Thank you for standing by my side and supporting me with my endless admiration for continuing my education. You have supported me through this difficult and sometimes frustrating process and encouraged me to keep my head high.

To my family: Thank you for always believing in me and supporting me in all of my decisions to continue my education. Your support is the key to my success.

Dr. Kathryn Underwood: Thank you for creating an environment filled with passion for learning, appreciation for growing, and space for making mistakes along the way. You have challenged me in ways I never imagined. I appreciate your time and expertise as this process would not have been the same without you.

Dr. Kathleen Peets: Thank you for supporting me and finding time to listen when I needed to talk things through. You helped ease the difficult process and inspired me to push boundaries and challenge my own thinking.

Dr. Mehrunnisa Ali: Thank you for the continuous support you provided as Program Director during the academic year and for setting up the MRP workshop which was very useful.

Heather Cowan and Lyndsay Macdonald: I am so grateful that I met both of you as you have made this journey what it is. This year has been filled with countless tears followed by uncontrollable laughter, but we managed to push through and succeed.

Research participants: This study could not have been accomplished without you volunteering your time and sharing your experiences. Thank-you. 


\section{Dedication}

To my amazing husband, Cristian, who stood by me through this entire process and who constantly offered me words of encouragement and support along the way.

To early childhood educators who dedicate their lives to working with children: you are blessed with the opportunity to educate and inspire young minds.

To children with disabilities: your worth is invaluable. 


\section{Table of Contents}

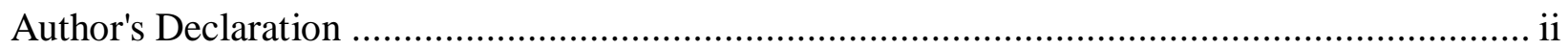

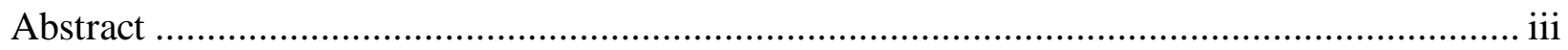

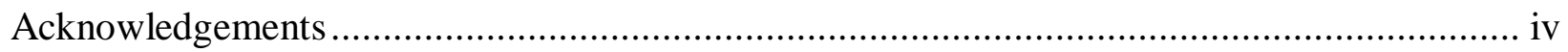

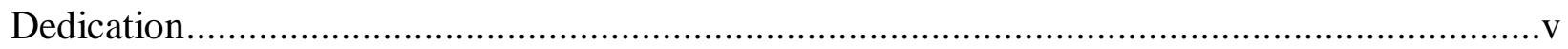

\section{Chapter 1}

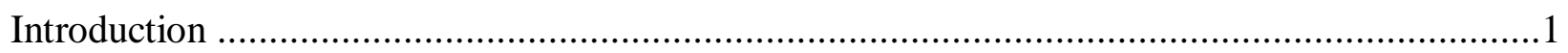

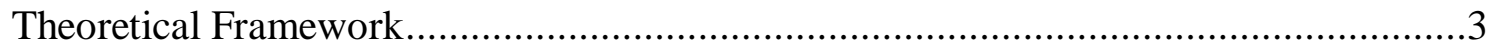

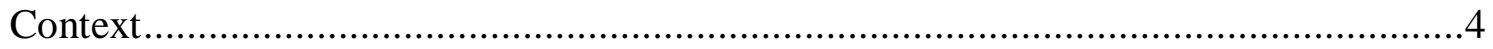

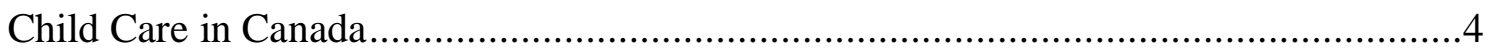

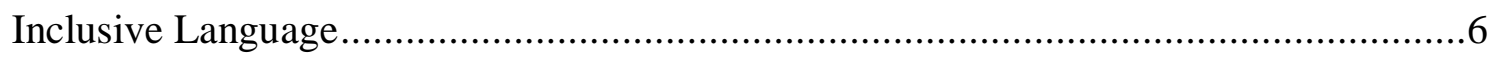

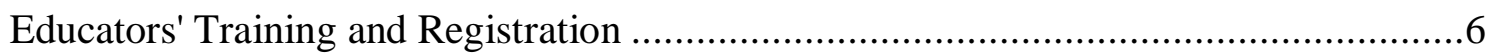

\section{Chapter 2}

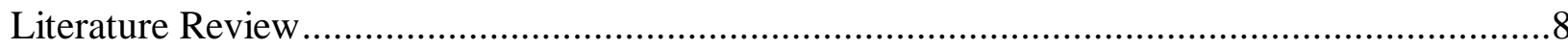

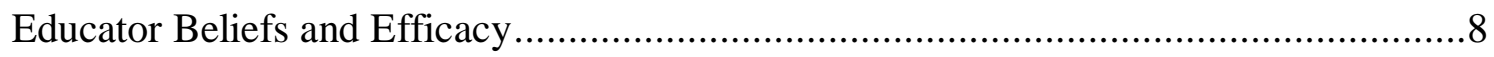

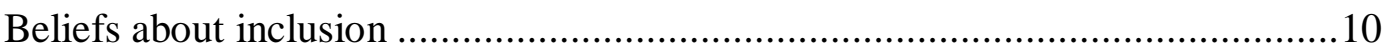

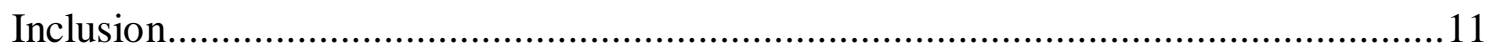

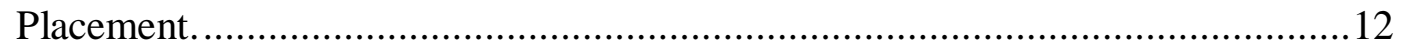

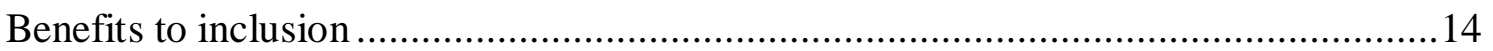

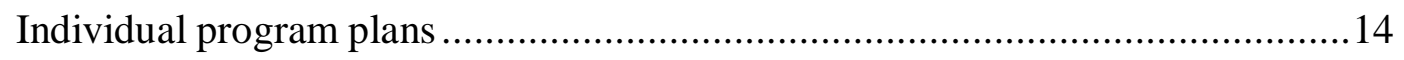


Barriers to inclusion ................................................................................. 15

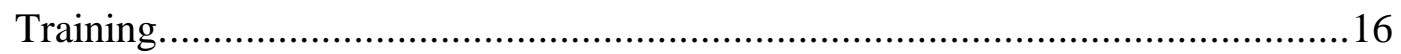

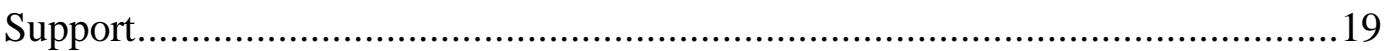

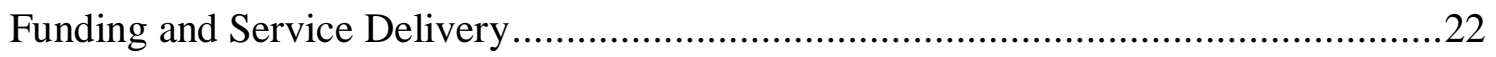

\section{Chapter 3}

Methods

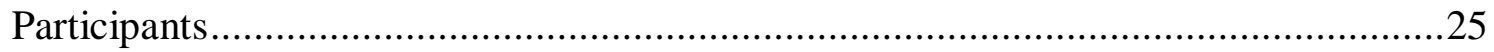

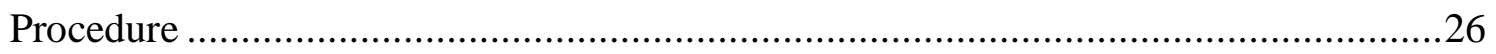

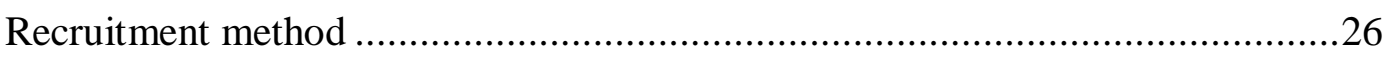

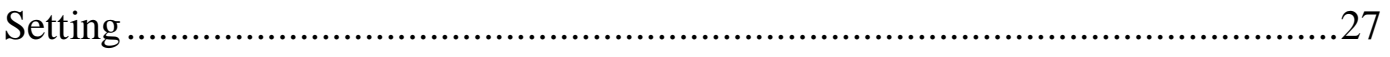

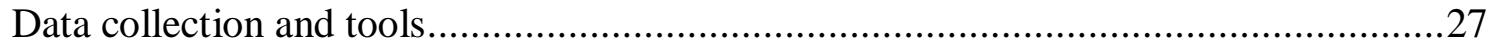

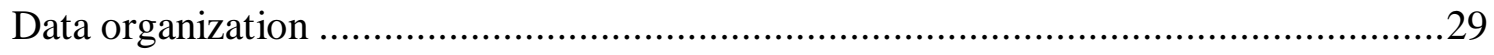

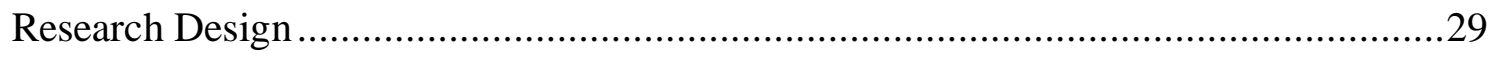

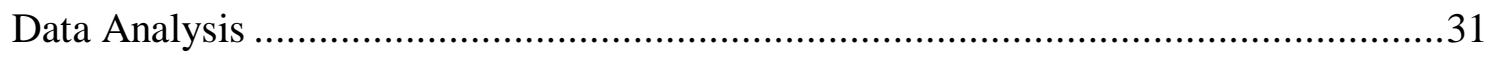

Chapter 4

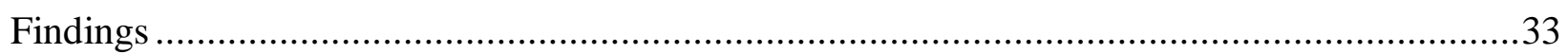

Participant characteristics .................................................................... 33

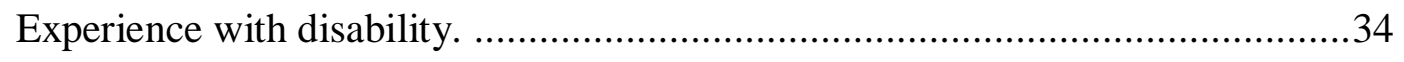

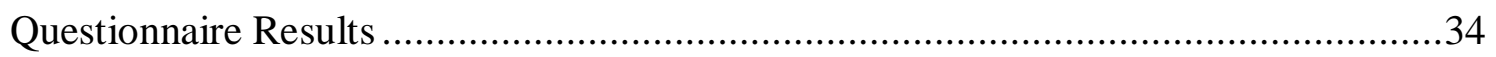

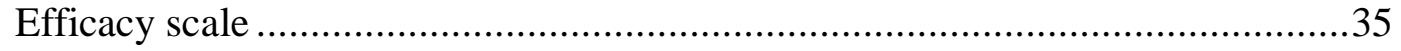


Disability and education questionnaire

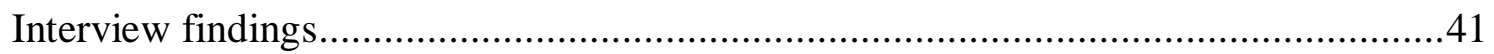

Early childhood educators' perceptions of inclusion ...................................................41

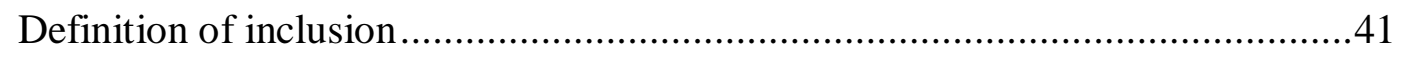

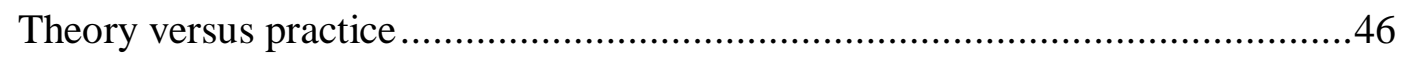

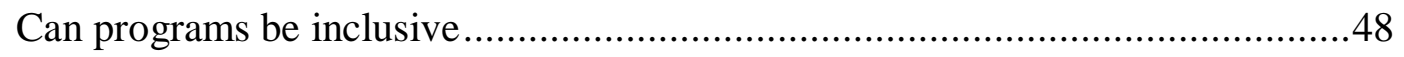

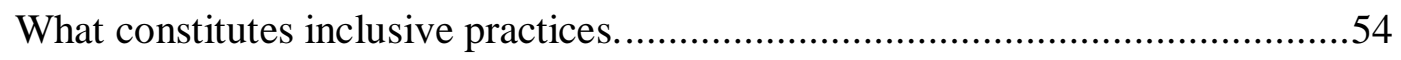

Knowledge and understanding of Individual Program Plans (IPP) …..........................58

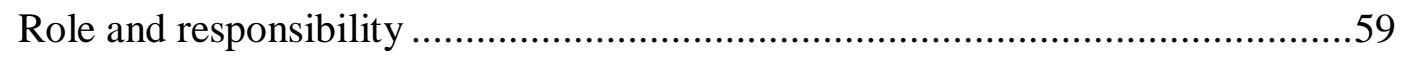

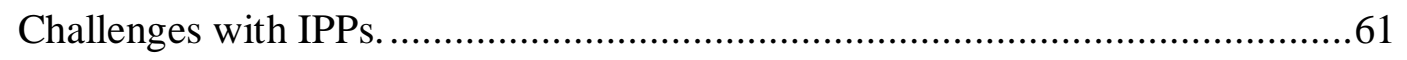

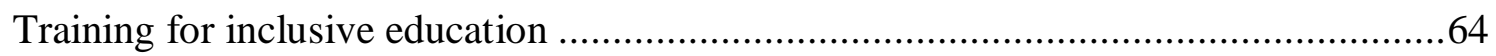

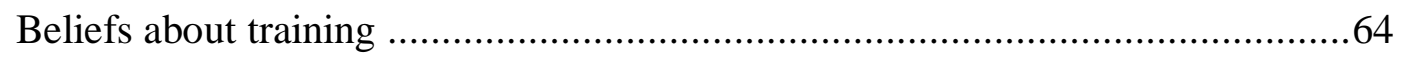

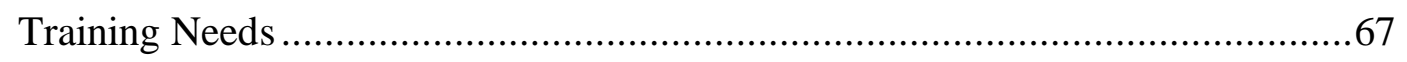

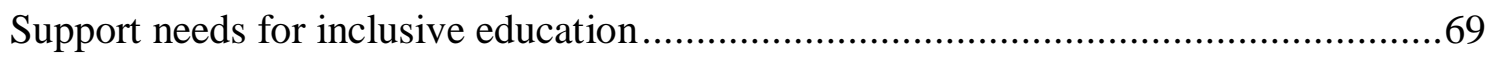

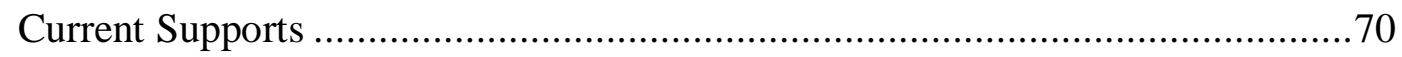

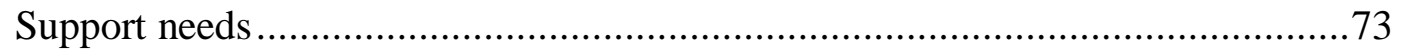

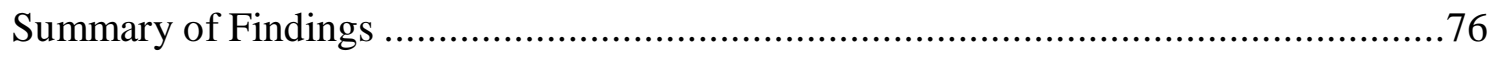

\section{Chapter 5}

Discussion.

Early childhood educators' perceptions of inclusion 
Individual Program Plans............................................................................ 82

Can programs be inclusive? ............................................................................... 83

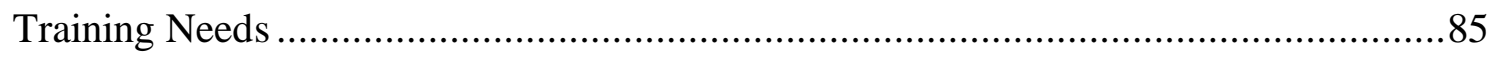

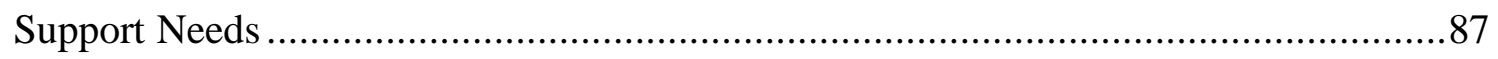

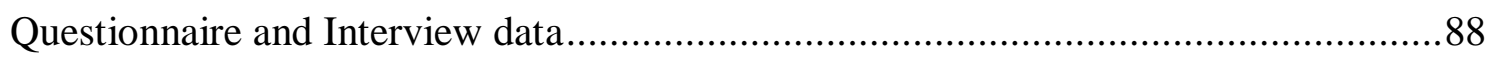

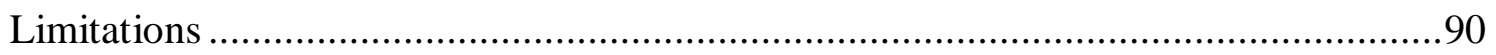

Future Research................................................................................... 91

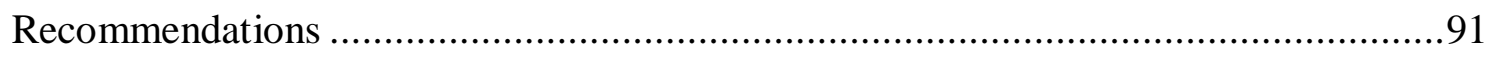

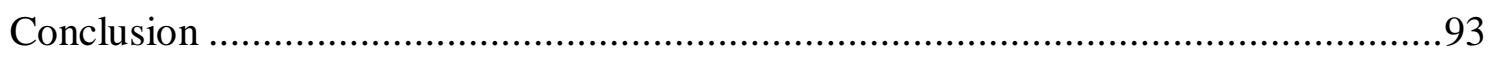

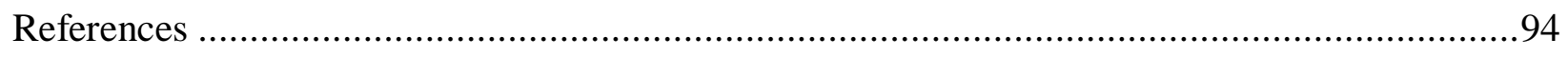

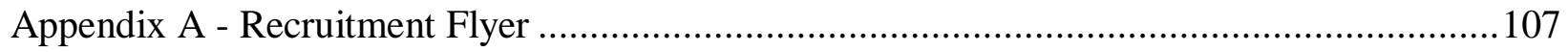

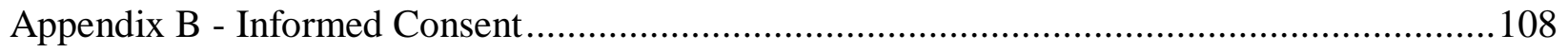

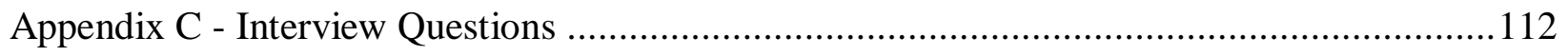

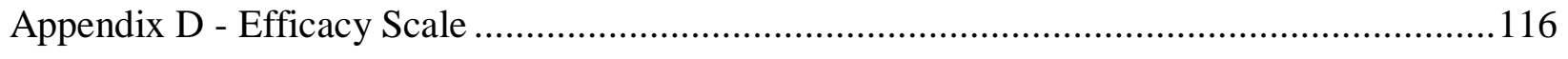

Appendix E - Disability and Education Questionnaire ............................................... 117

Appendix F - Participant Characteristics................................................................ 119 


\section{Chapter 1}

\section{Introduction}

This study explores early childhood educators' perceptions of their own training and support needs for practicing inclusive education. When society considers the rights, needs and contributions of all of its members, it is truly an inclusive society. In education, our very notions of equity and fairness rely on this concept of inclusion. It is not surprising then that inclusion and inclusive education are international priorities (Graham \& Slee, 2006) and frequently discussed topics in contemporary education (Goodfellow, 2012). UNESCO (1994) claims that inclusion is the most effective way to battle discriminatory attitudes and achieve education for all individuals and calls upon governments around the world to invest greater effort to achieve this goal.

Inclusion is a construct that examines full participation of children with disabilities in educational settings. The United Nations Convention on the Rights of the Child (UNCRC) (2006) "was the first human rights treaty to make specific reference to disability" and discussed how disability does not lie within the individual, but is a result of societal barriers (p. 2). Children with disabilities are impacted by "a combination of social, cultural, attitudinal, and physical obstacles" which act as barriers to their full participation and inclusion in society (UNCRC, general comment No. 9, 2006, p. 2).Furthermore, the Convention was also the first to dedicate a separate article 23 entirely to the rights and needs of children with disabilities (UNCRC, 2006). Although this doctrine is set in place, children with disabilities have been and continue to be excluded based on disability.

In Canada, children have historically been segregated from early childhood education and care, and society, solely based on the presence of a disability (Irwin, Lero \& Brophy, 2004). The 1960s gave rise to developmental preschools, for children with intellectual disabilities, and child 
development centres, for children with physical disabilities (Irwin, Lero \& Brophy, 2004). However, children who were blind, Deaf, had autism or specific health care needs were ineligible to attend preschool programs and were sent to alternate programs (Irwin, Lero \& Brophy, 2004).

It was not until the mid- to late-1970s that some child care centres started including children with special needs (Irwin, Lero \& Brophy, 2004). The curriculum set in place for children with special needs mirrored the special education program held in schools. Pull-out programs were offered to teach specific skill development and the Individual Program Plan (IPP) was used to measure and monitor children's progress. Around the same time as the Convention on the Rights of the Child (1989), training increased for integrated child care in Canada (Irwin, Lero \& Brophy, 2004). At the time when inclusion was implemented with a resource consultant model, more emphasis was placed on the idea that all children can learn within a group (Irwin, Lero \& Brophy, 2004). The resource consultant provided a variety of services from consultations to direct services within the centre.

While the 21 st century has seen federal and provincial support for inclusive child care (Irwin, Lero \& Brophy, 2004), the reality is that children with disabilities still face significant barriers in accessing inclusive programs (Killoran, Tymon \& Frempong, 2007). Killoran et al. (2007) interviewed directors of early learning centres in Toronto, Ontario and found that 59\% of directors would refuse a child based on disability. This finding supports Barton and Armstrong's (2001) conclusion that children with disabilities face greater inequalities in education in terms of choice and opportunity than most children, even though benefits to inclusion have been identified for all stakeholders. 
Research demonstrates that inclusion benefits children with disabilities and also positively influences others (Banerji \& Dailey, 1995; Heiman, 2004; Kucuker et al., 2006; Leatherman, 2007; Perlman, Kankesan \& Zhang, 2008; Short \& Martin, 2005; Weller \& McLeskey, 2000). Benefits include academic gains (Short \& Martin, 2005), social acceptance, (Kucuker, Acarlar \& Kapci, 2006; Short \& Martin, 2005; Thornton \& Underwood, 2012), collaborative environment (Hwang \& Evans, 2011; Mancini \& Layton, 2004; Rose, 2001) and empathy development (Banerji \& Dailey, 1995; Stoler, 1992). Research also shows that training (Bruns \& Mogharreban, 2007; Horne \& Timmons, 2009; Mancini \& Layton, 2004), support (Arceneaux Rheams \& Bain, 2005; Leatherman, 2007; Lohrmann \& Bambara, 2006) and funding (Frankel, 2004; Rose, 2001; Winzer \& Mazurek, 2011) are important factors that contribute to the benefits listed above. Training increases confidence and prepares educators for working with diverse populations within a classroom (Horne \& Timmons, 2009). Supports, whether from other professionals, managers or colleagues offer perspectives and resources for educators to use when working with children with disabilities in the program (Leatherman, 2007; Lohrmann \& Bambara, 2006). Finally, funding from the government increases opportunities for educators to access appropriate training such as workshops and professional development courses. It also determines the support available for children accessing the services in and out of the program (Frankel, 2004). All of these perceived barriers will be discussed in further depth in the literature review as they are pertinent to the research project.

\section{Theoretical Framework}

There are different perspectives on disability that either emphasize the medical or pathological traits of the individual (Barnes \& Mercer, 2001), or that examine the interaction of individuals with impairments in society, as in the social model of disability (Barnes \& Mercer, 
2001; Hughes, 2001; Shah, 2010). The social model of disability recognizes that societal barriers are impeding children's access from full participation (Bines \& Lei, 2011; Skinner \& Weisner, 2007). On the other hand, the medical model views disability as a problem stemming from individual characteristics or pathologies (Skinner \& Weisner, 2007). Researchers argue that society disables impaired individuals by creating and perpetuating social barriers (Barnes \& Mercer, 2001; Hughes, 2001). Barnes, Oliver and Barton (2002) go on to argue that according to the social model, disability is a socially constructed concept. Barton and Armstrong (2001) argue that societal barriers restrict access to "educational structures, school cultures, discourses, curricula, and pedagogy" which reproduces discrimination and exclusion within the larger society (p.703). Barriers created through ignorance or discrimination prevent children from actualizing their right to education (Shah, 2010). Moreover, the social model of disability does not ignore the existence of impairment but allows for those who are living with a disability to have opportunity to fully participate in social settings and in society. The social model of disability is the theoretical framework that guided the research project. The current study uses the social model of disability to identify the barriers that are restricting children with disabilities from participating in early childhood settings and also as a lens to view the data that will be analyzed. Despite critiques of the social model (Terzi, 2004 and Cole, 2007), it is nonetheless valuable to the current study in addressing issues of social barriers, which are the focus of the current investigation.

\section{Context}

\section{Child Care in Canada}

Canada fails to provide a universal child care system at the federal level (UNICEF, 2008). Quebec is the only province in Canada that has a universal child care system in place 
(Kohen, Dahinten, Khan, \& Hertzman, 2008). Most child care responsibilities fall onto provincial governments. The provincial government of Ontario is responsible for funding, licensing and developing policy to support the provision of licensed child care (Ontario Ministry of Education, 2013).

The current legislation that governs child care in Ontario is known as the Days Nurseries Act (DNA) (Ontario Government, 1990). The DNA enforces standards and regulations for operating licensed child care centres which are regulated and inspected on an annual basis. Parents and caregivers have the option of choosing between licensed and unlicensed child care centres, regulated home day cares, nursery schools, Ontario Early Years Centres, family resource centres, and child development centres (Ontario Ministry of Education, 2013), some of which employ early childhood educators to facilitate programming for young children. However, spots are limited and expensive, often leaving parents and caregivers to find childcare elsewhere, such as privately run home day cares (Kohen, Dahinten, Khan \& Hertzman, 2008). These researchers found that selection of child care arrangements vary depending on factors such as availability of spaces and cost. The issues pertained to accessibility are even more pronounced for families of children with disabilities as children have been excluded from child care solely on the presence of a disability (Killoran et al., 2007).

Many governments now have anti-discriminatory laws that protect the rights of people with disabilities (Barnes et al, 2002). For example, in Canada, the Canadian Charter of Rights and Freedoms, state that every individual is equal before and under the law without discrimination on the basis of mental or physical disability under section 15 Equality Rights (Canadian Charter of Rights and Freedoms, 1982). More specifically, the Ontario Human Rights Code is a provincial law that gives everybody equal rights and opportunities without 
discrimination. Section 1 of the Code guarantees the right to equal treatment in services without discrimination on the ground of disability (Ontario Human Rights Code, 2012, c.7). Killoran et al.'s (2007) findings are alarming because it illustrates that some child care centres are still excluding children even when federal and provincial laws are set in place to protect them from this type of discrimination.

\section{Inclusive Language}

The Division for Early Childhood Education (DEC) and the National Association for the Education of Young Children (NAEYC) (2009) articulate that "phrases such as 'children with special needs' and 'children with exceptionalities' are sometimes used in place of 'children with disabilities' (p.5). However, by definition these concepts are different from one another. The Convention on the Rights of Persons with Disabilities (2006) define persons with disabilities to "include those who have long-term physical, mental, intellectual, or sensory impairments which in interaction with various barriers may hinder their full and effective participation in society on an equal basis with others." (United Nations, 2006, Article 1). On the other hand, according to a position paper in the Division for Early Childhood (1993), "young children with special needs are those between birth and age 8 who have disabilities, developmental delays, are at-risk for future developmental problems, or who are gifted and talented" (Sandall, McLean \& Smith, 2000, Appendix C). In early childhood education, the term special needs is commonly used amongst early childhood professionals and will be used in the literature review where it is used in other studies, and in the findings where it was used in discussion with educators. In all other cases the term disability is used.

\section{Educators' Training and Registration}

In Ontario, early childhood educators have either a two-year ECE diploma from a Community College or a four-year ECE degree from a University or Community College 
affiliate. Until recently, early childhood educators were described as unregulated practitioners (Underwood \& Killoran, 2009). However, in 2007, the provincial government of Ontario passed the Early Childhood Educators Act, a piece of legislation that established the College of Early Childhood Educators (CECE) (College of Early Childhood Educators, 2012). The CECE is a self-regulatory body with a set of requirements and qualifications for early childhood educators who wish to be registered with the College. Members are responsible to practice in accordance with the Act along with abiding by the ethical and professional standards outlined by the Council of the College (College of Early Childhood Educators, 2012). To practice in the profession, it is a requirement that a person must be registered with the College in order to use the protected title Registered Early Childhood Educator (RECE) (College of Early Childhood Educators, 2012).

The subsequent chapter will present a literature review on educators' beliefs and efficacy, the concept of inclusion, including the benefits and barriers to inclusive education, followed by the research questions that guided the research project. 


\section{Chapter 2}

\section{Literature Review}

The following literature review discusses literature on educator beliefs, the concept of inclusion, and benefits and barriers to inclusive education. These topics are pertinent to the current research project as inclusion is complex both in how it is defined and how it is enacted. The literature relies on research that has been conducted both with elementary teachers and early childhood educators. Where both are referenced, this review will use the collective term "educators" for clarity.

Previous research has identified educator beliefs as playing an integral role in the existence of inclusive programs; therefore, it is crucial to understand how beliefs are constructed from a theoretical perspective (Bruns \& Mogharreban, 2007). Furthermore, a review of the literature suggests that there are many interpretations of inclusion, some scholars focusing on placement (Horne \& Timmons, 2009; Mancini \& Layton, 2004) while others arguing that inclusion is more than integrating children with special needs with their non-disabled peers (Graham \& Slee, 2006). Finally, benefits and barriers to inclusion are outlined from literature on educators' perceptions.

\section{Educator Beliefs and Efficacy}

Early childhood educators' beliefs are a contributing factor in the outcome of inclusion (Arceneaux Rheams \& Bain, 2005; Bruns \& Mogharreban, 2007; Ostrosky, Laumann \& Hsieh, 2006; Scruggs \& Mastropieri, 1996; Smith \& Smith, 2000). According to Bandura's social cognitive theory, the beliefs that individuals hold about their perceived abilities and about the result of their efforts influence their behaviour. Richardson (1996) defines beliefs as "a subset of a group of constructs that name, define, and describe the structure and content of mental states that drive a person's actions" (p.102). Since educators' perceptions influence their behaviour, 
how they perceive inclusion can impact their classroom practice (Ostrosky et al., 2006), and how they perceive disability can impact their beliefs about the ability to learn (Jordan, Glenn \& McGhie-Richmond, 2010). Such beliefs may be contextual rather than reflective of individual beliefs (Jordon, Glenn \& McGhie-Richmond, 2010), and reflect cultural norms or the attitudinal climate of the early childhood centre (Gibbs, 2007).

Individuals have a tendency to judge their abilities according to their actions (Erdem \& Demirel, 2007), which play a role in the understanding of one's self-efficacy belief. Bandura (1995) defines self-efficacy as "beliefs in one's capabilities to organize and execute the courses of action required to manage prospective situations" (p.2). Educators' self-efficacy consists of general and personal teaching efficacy: General teaching efficacy is an educator's belief that teaching influences student learning and personal teaching efficacy is an educator's belief in their own ability to affect student learning (Arceneaux Rheams \& Bain, 2005). Erdem and Demirel (2007) found that educators' self-efficacy is important in decisions regarding classroom organization and management, teaching approaches and providing motivation for children to learn. Woolfolk (1998) argues that self-efficacy theory predicts that teachers who have a high sense of efficacy work harder and are more persistent with difficult to teach children because they believe in their own abilities to teach and in the children's ability to learn. Self-efficacy provides "the foundation of human motivation, well-being and personal accomplishment because unless people believe that their actions can produce the outcomes they desire, they have little incentive to act or to preserve when they face obstacles" (Erdem \& Demirel, 2007, p. 576). Given that attitudes originate from established beliefs, the current research study will focus on early childhood educators' beliefs about inclusive education and whether or not it has an influence on educators' practice. 
Beliefs about inclusion. While there is a body of research on elementary school teachers' beliefs about inclusion, there is a lack of literature available about early childhood educators' beliefs about inclusion from early childhood settings. From the literature that is available, early childhood educators have both positive and negative beliefs about inclusion (Arceneaux-Rheams \& Bain, 2005; Leatherman, 2007; Mancini \& Layton, 2004; O'Rourke \& Houghton, 2009; Thornton \& Underwood, 2012).

Mancini and Layton (2004) found that most early childhood educators were willing to include children with disabilities into the classroom and that all children can contribute within the classroom, regardless of disability. Results further indicate that some educators had concerns over their own limitations rather than the needs of the child. These researchers concluded that additional training may be needed to address this concern. In a similar study, Leatherman (2007) included educators who only expressed positive beliefs about inclusion, in order to analyze positive aspects of inclusive classroom environments to illustrate the significance of inclusion. The results of her study indicate that educators expressed concerns about inclusion but that the overall reward, being a positive learning environment for all, outweighed the challenges. Training and support from administrators were raised as contributing factors to the success of inclusion. In relation to the current study, these findings suggest that training and support needs are fundamental to inclusive practices as educators need to feel confident in their abilities to teach.

More recently, Thornton and Underwood (2012) found a range of beliefs amongst early childhood and elementary educators. The educators with positive beliefs about inclusion said that inclusion afforded social benefits for children with disabilities such as social acceptance and academic functioning. Some educators communicated challenges with inclusive practices with 
regard to the theoretical concept of inclusion and it's positioning in practice. For example, one educator stated: "you can look at a definition and say absolutely I agree with it but then in practice it is very, very different" (Thornton \& Underwood, 2012, p.8). The four educators that were interviewed expressed beliefs that reflect medical model approaches where the disability resides in the individual, and social model approaches where the disability is attributed to the interaction with the environment. Similarly, the current research study will evaluate educators' beliefs about inclusion to see whether they reflect the social or medical model in order to see how educators conceptualize inclusion.

Given that beliefs play a significant role in inclusive practice, changing perspectives can potentially help combat negative attitudes held by some early childhood educators. Educators need to have a particular mindset that sees the child before the disability (Allen, Paasche, Langford \& Nolan, 2011). Viewing the child first before the disability will enable educators to focus on finding appropriate ways to plan according to the developmental needs of the child. Educators who have positive beliefs are more likely to practice inclusive education because they fundamentally believe that all children should be included. Understanding the concept of inclusion provides educators with the necessary theoretical underpinnings and enables educators to engage with all children in their class.

\section{Inclusion}

Inclusion has various meanings and interpretations as evident within the literature (Barton \& Armstrong, 2001; Frankel, 2004; Graham \& Slee, 2006; Ostrosky, Laumann \& Hsieh, 2006; Sikes, Lawson \& Parker, 2007; Slee, 2001). Within the body of literature on inclusion, some scholars are concerned with placement (Mancini \& Layton, 2004; Horne \& Timmons, 2009) while others argue that placement alone in a regular program does not constitute inclusive 
practices (Graham \& Slee, 2006). Slee (2001) posits that the mere absence of a language for inclusive education increases potential risk for political misappropriation of the concept. For some theorists, the process of inclusion is concerned with identification and removal of barriers for children with disabilities who are at risk of under achieving, being marginalized or excluded (Barton \& Armstrong, 2001; Shipley, 2002; UNESCO, 2005). In this project, the researcher agrees that inclusion is more than placement and uses the social model of disability as a lens to direct the research project. UNESCOs (2005) definition of inclusion guides this study because it governs international guidelines and policies for inclusive education and it is consistent with the theoretical framework presented above:

addressing and responding to the diversity of needs of all learners through increasing participation in learning[...] and reducing exclusion within and from education. It involves changes and modifications in content, approaches, structures, and strategies, with a common vision which covers all children (p.13).

Placement. Mancini and Layton (2004) posit that inclusion supports the belief that children with disabilities need to spend the majority of the day in the general classroom being educated alongside children without disabilities. In addition, children with disabilities are to be incorporated into regular programs to the maximum extent possible. However, the current study aligns with Barton (1997) and Allan's (2008) belief that views inclusion as more than merely placement, as its purpose is to increase participation and remove barriers for children with disabilities. Barton (1997) argues that barriers which exist in society need to be recognized, challenged and discarded. The purpose of inclusion is to foster meaningful opportunities for all children regardless of disability (Barnes, Mercer \& Shakespeare, 1999) by empowering individuals and celebrating differences in dignified ways (Barton, 1997). 
Graham and Slee (2006) argue that "to include is not necessarily to be inclusive" (p. 3). Shifting children around on the 'educational chessboard' is not an inclusive practice (Graham \& Slee, 2006, p.3). Formerly, "inclusive education was offered as a protest, a call for radical change to the fabric of schooling. Increasingly it is being used as a means for explaining and protecting the status quo" (Graham \& Slee, 2006, p. 2). Graham and Slee (2006) argue that there is an implied centred-ness to the term inclusion by seeking to include 'the Other' into an already preexisting illusionary space (p.3). These researchers further posit that scholars need to clarify the discourses of inclusion, to distinguish between the means and ends of education. There needs to be a drastic shift from looking for the markers of difference to creating a space that sees all children as different, therefore eradicating the notion of Other. This change in thinking needs to arise from educators' beliefs and attitudes and how they create curriculum that is representative of all the children within their classroom.

Inclusive education is more than placement, it is about access, teaching practices, fair treatment from others, including other children, staff, families and the broader community (Underwood, Valeo, \& Wood, 2012) and having a good support system (Horne \& Timmons, 2009). Inclusion begins with access to early childhood centres that use a range of teaching approaches, meeting the needs of all the children in the program. Access, as Killoran et al (2007) found, can be difficult for families of children with disabilities. The ethos of inclusion is to create meaningful opportunities for all children regardless of disability (Barnes et al., 1999) and not stigmatize and exclude them from their peers. The current study aims to evaluate the definitions of inclusion given by early childhood educators to identify the ways in which educators define inclusion and practice inclusive education. 


\section{Benefits to inclusion}

A considerable number of benefits to inclusion have been identified and extensively researched within the literature. Additional themes, from those presented in the introduction that emerged from the literature include social acceptance (Banerji \& Dailey, 1995; Hall \& Niemeyer, 2000; O'Rourke \& Houghton, 2009; Perlman, Kankesan \& Zhang, 2008); building self-esteem for children with special needs (Banerji \& Dailey, 1995; Kucuker, Acarlar \& Kapci, 2006); positive experience for all (Kucuker, Acarlar \& Kapci, 2006; Leatherman, 2007; Perlman, Kankesan \& Zhang, 2008); and, collaboration within teams and children themselves (Hollingsworth, Able Boone \& Crais, 2009; Leatherman, 2007; Mancini \& Layton, 2004; Rose, 2001). As evident in the literature, there are many benefits to inclusion for all individuals. An important part of collaboration includes creating individual program plans for children with disabilities in order to create an environment that meets individual needs.

Individual program plans. Children in early childhood programs that have been identified as having a disability usually have an individual program plan (IPP) that is modified to their specific needs. Having an IPP affords the early childhood educator with the tool to help accommodate the program to meet the needs of the individual child. The individual program plan is "an approach to providing services to individuals with special needs" (Allen, Paasche, Langford \& Nolan, 2011, p.272). The process involves creating a written plan outlining the child's strengths, specific needs, and interests. Early childhood educators are an important asset in the observation, implementation and evaluation of individual program plans. Educators should evaluate the appropriateness of each child's IPP and therefore are central to the entire process. The earlier a need is identified, the more likely appropriate accommodations can be made for the child (Allen et al., 2011). A child entering a child care centre with an identified special need 
should have an IPP created that the educators need to follow in order to be inclusive of that individual child.

Hollingsworth, Able Boone and Crais (2009) argue that to implement a functional IPP, interdisciplinary collaboration is necessary. Interdisciplinary service delivery includes professionals from different disciplines working together to provide adequate support to children and their families (McWilliam, 2005). To be most effective, IPPs should specify individualized instructional strategies which enable children to be fully engaged in programs (Hollingsworth, Able Boone \& Crais, 2009). Furthermore, Kosko and Wilkins (2009) investigated the relationship between educators' professional development hours, years teaching students with IEPs ${ }^{1}$, and self-perceived ability to adapt instruction for students with IEPs. Results of the study indicated that increases in professional development resulted in increases in educators' level of efficacy in their ability to adapt instruction for students with IEPs. Although on average, the study found that teachers felt only moderately comfortable adapting instruction. The current study will investigate the role and responsibilities of educators in the creation, implementation and evaluation of the IPP process.

\section{Barriers to inclusion}

Several concerns were identified in the literature as barriers to inclusion. Instead of reiterating all of the barriers that were raised in the body of research, this literature review will cover the barriers that are pertinent to the research study. Barriers include: training (Bruns \& Mogharreban, 2007; Forlin \& Chambers, 2011; Horne \& Timmons, 2009; Mancini \& Layton, 2004; Sikes, Lawson \& Parker, 2007), support (Arceneaux Rheams \& Bain, 2005; D'Alonzo, Giordano \& Vanleeuwen, 1997; Forlin \& Chambers, 2011; Horne \& Timmons, 2009;

\footnotetext{
${ }^{1}$ An Individual Education Plan is a written plan describing the special education program and/or services required by a particular student (Ontario Ministry of Education, 2000)
} 
Leatherman, 2007; Lohrmann \& Bambara, 2006) and funding (Frankel, 2004; Rose, 2001). The aim of the current study is to elicit the type of training and support needs that educators want to receive and why more funding is required and where it should be allocated.

Training. Training has been identified as a barrier to inclusive education since many educators identify that they lack appropriate skills that are necessary to work with children with disabilities. An effective educator can meet the needs of all the children in the program, yet many educators feel they are not adequately prepared. Several scholars argue that educators lack adequate training when working with children with special needs in inclusive programs (Bruns \& Mogharreban, 2007; Horne \& Timmons, 2009; Mancini \& Layton, 2004; Sikes, Lawson \& Parker, 2007). The subsequent paragraphs will examine training needs that were identified among different empirical research studies.

Mancini and Layton (2004) conducted a study that explored the perceptions of nine early childhood educators regarding the inclusion of children considered medically fragile, through structured interviews. Educators felt that they had limited experience working with children who were mentally fragile and wanted more thorough training. Educators wanted to receive more training on how to handle medical situations, on various disabilities, how to prepare other students and on stress management (Mancini \& Layton, 2004). This study is important because it identifies the need for specialized training in order for educators to have the confidence to be able to meet the needs of all of the children in the program. It further identifies the types of training that may be required for educators to feel prepared for inclusive environments.

Similarly, in a study conducted by Bruns and Mogharreban's (2007), participants also identified the need for additional training. These researchers conducted a quantitative study using the STARS (Support and Technical Assistance through Relationship and Skill-building) Needs 
Assessment tool for gathering data on inclusion-related beliefs and training needs from educators' perspectives. One hundred and twenty educators participated in the study and results indicate that the majority of ECE professionals in the study believed all children are capable of learning and that children with disabilities should receive services alongside their typically developing peers. However, Bruns and Mogharrdban (2007) noted that participants would like to see more training about behavioural issues and communication strategies, as these are areas that can assist educators to better facilitate positive environments for all children. This study is relevant as it identified training needs for ECEs, while using a quantitative tool to measure their beliefs. The current study uses triangulation to measure educators' beliefs about disability and education and a self-efficacy questionnaire to measure their beliefs about being educators.

Horne and Timmons (2009) conducted a qualitative study on educators' perceptions of the impact of inclusion on children with special needs. Twenty participants from Prince Edward Island in Canada who volunteered to participate were randomly selected to take part in the study. These researchers found that if teachers were not familiar with specific disabilities, they felt frustrated and guilty in not being able to provide the best for their students. The major concern that was highlighted in the data was associated with training needs. Nineteen out of twenty-five participants $(76 \%)$ were concerned with teaching children with a wide range of needs in one class; sixty percent felt they were not adequately trained to work with diverse needs; and sixty percent believed they lacked training on how to manage a diverse classroom (Horne \& Timmons, 2009). Lack of training was identified as a barrier to effectively meeting the needs of all the children in the class. Although this study measured elementary school teachers' perceptions, it is still relevant to the current study as teachers and educators hold similar beliefs within the body of literature on inclusion. 
Sikes, Lawson and Parker (2007) performed a qualitative narrative and autobiographical investigation on educators' perceptions of inclusion. Participants were asked to discuss what inclusion meant to them and to share both positive and negative experiences about inclusive practices. The researchers found discrepancies in individuals understanding and experiences of inclusion. Their understandings of inclusion aligned with aspects of government policies, while their practices were guided by their own experiences in the classroom (see Sikes et al., 2007). This study is important because in Ontario there is no formal policy on inclusion in early childhood education. Without a formal inclusion policy each early childhood educator may define inclusion based on the teachings of the Community College or University that they attended, which can result in different understandings and interpretations of inclusion.

Baker-Ericzen, Mueggenborg and Shea's (2009) study examined training and its impact on educators' perceptions of their ability to be inclusive. Four sessions were made available to all participants, with questionnaires given to participants pre- and post training sessions. Upon completion of training, results indicate that there was a shift in teachers' perceptions of inclusion indicating that teachers felt more competent and had more positive beliefs about inclusion after training. This finding suggests that training produces significant gains and can have an effect on educators' beliefs.

Although some educators feel they have adequate training, many educators feel they lack the appropriate training to work with children who have disabilities in an inclusive environment. From the studies described above, it is clear that more training is required for educators to feel confident in their abilities to teach children with disbilities. When educators receive specialized training, as seen in Baker-Ericzen et al's study, significant gains in attitudes are described. The current study will ask educators particular questions during interviews about their training and 
training needs to elicit specific information regarding the topic since previous research illustrates that early childhood educators are not confident with their current level of training.

Support. Another barrier that was evident in the body of literature on inclusion was support needs. Support needs are commonly reported as contributing factors to the success of inclusion (Arceneaux Rheams \& Bain, 2005; D'Alonzo, Giordano \& Vanleeuwen, 1997; Horne \& Timmons, 2009; Leatherman, 2007; Lohrmann \& Bambara, 2006). Support needs include having access to additional staff, managers/supervisors, and resource consultants. These are the most cited supports although they are not the only supports available to early childhood educators.

Leatherman (2007) conducted a study in which all participants reported that support from administrators was a contributing factor to the success of inclusion. Participants explained that supportive administrators made the program successful by connecting staff to therapists and resource agencies to help educators feel successful in the classroom. Hammond and Ingalls (2003) found that the availability of support from administration and resource teachers were important factors that contributed to successful inclusive classrooms. Being able to access resources when needed was the confounding factor that made educators successful. These studies are pertinent to the current research as each child care centre employs a manager whose role is to support early childhood educators with inclusive education, among other responsibilities. The current study will investigate how managers in the current study support early childhood educators in the centre by asking managers specific questions related to their roles during interviews.

Arceneaux Rheams and Bain (2005) investigated the perceptions and attitudes of early childhood educators toward social interaction interventions suitable for children with special 
needs in inclusive settings. Study results indicate that the majority of educators had positive beliefs towards inclusion. However, participants were aware that further training is required to ensure success. Low levels of satisfaction were reported for support that was being received from administration. The authors suggested that supervisors need to find ways to increase assistance in the room in order to increase educators' attitudes about educating children with special needs.

Lohrmann and Bambara (2006) researched elementary educators' beliefs about essential supports needed to be inclusive of children with special needs. Fourteen educators were interviewed on three separate occasions guided by semi-structured interview protocols. Results indicate that educators were apprehensive about including children with special needs into their classrooms. To overcome the challenge, educators discussed levels of support that they would like to receive in order to be inclusive of children with special needs. Participants agreed that there needs to be a school-wide culture of support and a clearly articulated vision for inclusion. In-class support was vital as assistance would alleviate some of the stress educators were feeling. Support personnel would be required to help with material adaptations, implementing behaviour strategies and providing one-on-one care (Lohrmann \& Bambara, 2006). In addition, direct assistance from administrators was seen as a critical factor described by the majority of teachers. Lohrmann and Bambara (2006) found that administrators need to be willing to personally get involved and take appropriate actions when required. This study suggests that administrators need to have an active role in supporting educators by providing necessary supports to staff when needed.

Horne and Timmons (2009) investigated the impact of inclusion on children with special needs from the perceptions of elementary school educators. The authors concluded that educators felt they need more support from supervisors and more planning time. Supervisors need to 
allocate time for planning with resource consultants, be leaders at meetings, and provide special education support. All of the educators surveyed revealed that planning time was important for additional meetings with parents, staff or resource teachers to develop Individual Education Plans (IEPs) or with other professionals (Horne \& Timmons, 2009). The current study will elicit specific information on individual program plans (IPPs) and discuss the specific roles and responsibilities of both managers and frontline staff as research has demonstrated the importance of managerial involvement in inclusive education.

Hunt, Soto, Maier, Liboiron and Bae (2004) studied the effectiveness of a collaborative teaching approach on the engagement, development and learning of preschoolers with special needs. Participants suggested that the collaborative process increased opportunities for educators to share their expertise and perspective with others that benefited the child. They stated that regular meetings increased accountability and monitored consistency with implementing plans. Results further indicate that benefits were evident for children within the program. There were substantial decreases in the levels of non-engagement in class activities for several of the children, and child-initiated interactions increased. Therefore, working with support staff, such as resource consultants and room partners may help educators increase confidence in their teaching abilities and ultimately lead to gains for children with disabilities within the program.

In summary, these studies identify the need for additional support in order for educators to feel successful in the classroom. The research also illustrates that when educators work with resource consultants and specialists, there are gains not only for educators but most importantly for the children within the program. However, supports are given based on funding that is made available to centres and staff members. 


\section{Funding and Service Delivery}

Funding and services for children with disabilities takes many forms in Ontario (Underwood \& Killoran, 2009). Resource Consultants (also called Resource Teachers, Developmental Consultants, Early Interventionists) are available in most licensed child care settings, and some family support, and family literacy programs. Early intervention, or specialized therapeutic programs are sometimes delivered in community settings, but often are done in clinical settings. The degree to which early intervention programs collaborate with other programs, such as child care and family support, is variable (Underwood \& Killoran, 2009). This wide range of services leads to mixed approaches in practices and a lack of consistency in programming (Underwood \& Killoran, 2009). This study, however, focuses on child care inclusion.

Frankel (2004) conducted a comparative study looking at the barriers and supports for inclusion based on site visits in Canada, the United States and Australia. Focusing on Ontario, Frankel (2004) hypothesized that a lack of government funding at the federal, provincial and municipal level creates barriers to full inclusion. Participants noted that the various funding mechanisms available to support inclusion were difficult to access and navigate (Frankel, 2004). Furthermore, the identification, assessment, and labelling process is critical to receiving funding for services (Frankel, 2004) and this process takes time. A child's eligibility to receive additional services is usually based on assessment results and level of disability (Frankel, 2004). Therefore, it may be difficult for children who have not been diagnosed to get the proper resources they require. In Canada, most provinces provide funding for resource consultants in child care centres (Frankel, 2004); however, getting the proper resources may be difficult without the appropriate documentation that is needed to buy specific equipment or materials. Funding also provides the 
opportunity to child care centres to access resources and support that are significant in helping early childhood educators facilitate curriculum plans appropriate for all levels of learning within the classroom.

\section{Summary of findings}

From the literature review it is apparent that there are many important components to practicing inclusive education. While many interpretations of inclusion exist, for the purpose of this research, inclusion is identified as being more than placement. It is about responding to the diverse needs of all children in the program through active participation. It aims at reducing exclusionary provisions for children with disabilities and makes appropriate accommodations within the environment to meet the needs of all the children in the program. In its history, Canada has seen periods of time where children were excluded on the basis of disability. However, in more recent years children are being included more often but it is still difficult for some children with disabilities to access services. Literature on beliefs demonstrates that generally educators have positive beliefs about including children but lack the appropriate training that is required to be successful with inclusion. In addition, research suggests that educators require additional supports to help ameliorate the process. Research studies further demonstrate that when specialized training and supports are available, positive outcomes are described for all participants. The current study aims at identifying specific training and support needs of participants to help answer the following research questions:

1. How do early childhood educators conceptualize inclusion and what are their classroom experiences?

2. How satisfied are early childhood educators with their level of training and support needs for inclusive education? 
3. What type of training do early childhood educators want to receive and what support needs would they like to see more of to increase inclusion for children with disabilities? 


\section{Chapter 3}

\section{Methods}

The purpose of the current research project is to gain insight into early childhood educators' perceptions of their training and support needs for inclusive education. Early childhood educators and managers were recruited from six early childhood centres across Toronto, Ontario. A qualitative interview method, and triangulation with questionnaires were used as the research methods. Open-ended interviews were the primary source of data collection followed by two supplementary questionnaires that were filled out by each participant. The interviews were transcribed verbatim and group results were recorded for questionnaire responses. Data were organized, coded and analyzed using a thematic approach. Themes came from the topics identified in the literature and elicited through the interview questions, as well as emergent themes that are discussed in the findings chapter of the research study.

\section{Participants}

Fifteen frontline staff and five managers from six early childhood centres across Toronto, Ontario participated in the study. All participants are registered early childhood educators. Criteria for participation included: 1) registration with the College of Early Childhood Educators; and 2) past or current experience working with children with disabilities in an inclusive environment. Sixteen registered early childhood educators and five managers who are also registered early childhood educators responded to the recruitment flyer, however, only fifteen

early childhood educators and five mangers met the applicable criteria and were included in the study. One participant was not registered with the College of ECEs and was not used in the research because she did not meet the required criteria. 
The sample consisted of two males and eighteen females. Early childhood educators who participated in the study currently work with children in toddler to school-aged rooms. The highest level of participants' education varied from having a diploma in Early Childhood Education ( $n=17)$, Bachelor of Arts degree in related disciplines $(n=6)$, teachers college $(n=1)$, to one participant with a Master's degree that was unrelated to the field of early childhood education.

\section{Procedure}

Recruitment method. After receiving ethics approval from the Research Ethics Board (REB) at Ryerson University, convenience sampling was used to recruit participants from six early childhood centres across Toronto. The initial recruitment strategy involved the researcher emailing a manager of a child care centre who she knows professionally to distribute the recruitment flyer to staff members of both the centres she manages via email. Seven early childhood educators responded to the recruitment flyer and agreed to participate in the study. The researcher then asked the same manager to send the recruitment flyer via email to other child care managers within Toronto. The flyer was sent to six managers, four of whom contacted the researcher via email. The researcher then requested that those managers send the recruitment flyer to their staff members. Nine early childhood educators individually contacted the researcher via email. One individual was not registered with the College, therefore did not meet the criteria for participation. Eight individuals met the criteria to participate in the study. A description of the study was sent to each participant (Appendix A) along with the consent form (Appendix B) and ethics approval. Participants were given the opportunity to carefully read the consent form and were encouraged to ask any additional questions about the study. Individuals were also 
reminded that participation was voluntary and if they chose not to participate, it would not affect their relationship with the early childhood centre or Ryerson University.

Setting. Meetings were scheduled on an individual basis and were held at locations that were convenient for the participants, including at local libraries and some took place at the child care centres, at the request of the participants. Meetings that were held at the child care centre were conducted in a private office during lunch breaks. Interviews ranged from twenty to fortyfive minutes in length, depending on individual responses.

\section{Data collection and tools}

Data collection consisted of an interview and two questionnaires that were completed in person. A semi-structured interview using open-ended questions was conducted with each participant. The questions were developed to specifically extrapolate information about training and support needs from early childhood educators' perspectives and to elicit their perceptions of inclusive education (the interview protocol is available in Appendix C). In a semi-structured interview, the interviewer and interviewee participate in the interview, constructing questions and answers through a discourse of multifaceted dialogue (Qu \& Dumay, 2011). Open-ended questions were chosen because they allow more fluidity in the interaction between the researcher and the participant (Marvasti, 2004). In this format, participants are not constrained to choosing from a pre-selected range of answers; rather they can elaborate and connect it with other issues relevant to the conversation (Marvasti, 2004). Semi-structured interviews provide a general direction and allow participants to respond in their own way (Marvasti, 2004). This method also allows the researcher to probe with additional questions to get a more in-depth and thorough explanation from the participant. All of the interviews were audio-recorded and the researcher 
took additional notes throughout the interview. When the interview was finished, participants were asked to complete two short questionnaires.

The two questionnaires were given to each participant at the end of the interview; one on self-efficacy (Appendix D) and one on disability and education (Appendix E). The questionnaires were a supplementary quantitative component that contributed information about constructs that are known to be factors in inclusive education practice. These questionnaires focus on educator beliefs which are thought to influence peoples' behaviour (Bandura, 1986). As described in the literature review, Bandura's social cognitive theory posits that the beliefs that individuals hold influences their behaviour. Therefore, collecting data on educators' self-efficacy and their beliefs about disability and education will add another dimension to the results.

The self-efficacy questionnaire was adapted from Gibson and Dembo's (1984) selfefficacy scale and was modified to reflect early childhood education terminology. The modified version contains fifteen questions that measure educators' self-efficacy. The purpose of using this tool was to better understand the self-efficacy of this group of educators in the field. The disability and education questionnaire was adapted from the National Disability Authority (2006) and consists of five questions (with statements imbedded) that measure beliefs about disability and education. The original questionnaire contains six sections that pertain to disability. However, for the purpose of this study, the researcher was only interested in measuring beliefs specifically related to education. The questionnaire was then adapted to reflect early childhood education terminology. Since beliefs have an influence on shaping educators' perceptions (Jordan \& Stanovich, 2003; Mulder, 2010) it is valuable to gain an understanding of educators' beliefs about disability and education for the purpose of this study. 
Questionnaires were given to all participants at the end of the interview. The researcher stepped out of the room, while the participants completed the questionnaires to give each participant privacy. Questionnaires were then placed in an envelope to ensure confidentiality. Only group responses were recorded and analyzed in the research project.

\section{Data organization}

All interviews were audio-recorded and transcribed verbatim. During transcription, pseudonyms were used to protect the identity of the participants and the information that was obtained. Only the researcher and the faculty supervisor had access to the raw data and it was stored on a password protected data key for transportation, and then on a password protected computer or in a locked filing cabinet in the supervisor's office at Ryerson University. All hard data (informed consent and questionnaire response forms) were kept in a locked filing cabinet in the supervisor's office at Ryerson University.

\section{Research Design}

The research was qualitatively driven with a quantitative supplementary component, a method described by Morse and Niehaus (2009). A qualitative approach was the primary focus of the research, as the researcher was interested in exploring how specific individuals give meaning to their experiences. Two related questionnaires were given to each participant which was the supplementary quantitative component that added to the research. Since the quantitative component violates the necessary principles of sample size and random sampling (Morse \& Niehaus, 2009), the results from the questionnaires cannot be generalized beyond the sample of the study and are viewed as a limitation. The results, however, provide a supplement to the qualitative data and provide important context for the interview data. An inductive style influenced the scope of the research as the purpose was one of discovery and exploration (Morse 
\& Niehaus, 2009) with a focus on delivering individual meaning about complex situations (Creswell, 2009). The quantitative component was used to add dimension and rigor to the study. According to Torrance (2012), no single method can provide a full picture of the phenomena under study; therefore, more methods are used to aid in the process. The present study employed data triangulation, a type of triangulation described by Denzin (2012) which involves the use of mixed data sources. Triangulation allows the researcher to see several dimensions of a phenomenon (Flick, 2007) and acts as a verification tool to test the validity among connections (Konecki, 2008). Triangulation was used to increase confidence in the results of the research gathered (Konecki, 2008) and put the data into a more comprehensive explanatory framework (Mertens \& Hesse-Biber, 2012). Torrance argues (2012) that triangulation brings a more comprehensive representation of the investigation. By employing different data sources within one study, it will add breadth to the results.

Triangulation was used in the current study as the researcher gathered information using different tools to understand participants' beliefs about inclusion. The disability and education questionnaire was used to understand individuals' belief about children with disabilities and the efficacy questionnaire aimed to measure educators' efficacy about their practice. Finally, openended interviews were used to elicit specific information on educators' beliefs about working with children who have disabilities in early childhood settings and how they practice inclusive education. Data gathered from all three sources will provide information about the relationship between educator beliefs about their practice, their beliefs about disability and education and their experiences in working with children with disabilities in the context of early childhood. 


\section{Data Analysis}

Data were analyzed using a process of thematic analysis described by Braun and Clarke (2006) as a qualitative method which identifies patterns within the data. This analytical method is a flexible tool providing potential to offer rich and detailed description of data (Braun \& Clarke, 2006). Analysis began with the transcription of individual interviews. It is in the process of transcription that, according to Lofland, Snow, Anderson, and Lofland (2006), the researcher "hears" what the respondent has said and where analytical insights take place. Once all interviews were transcribed, the researcher immersed herself in the data by reading in an active way and looking for meanings and patterns. Immersion functions as a type of opening coding, or a first review of the collected data (Neuman, 2006). During the second phase of analysis, initial codes were created. Codes were data-driven (Braun \& Clarke, 2006) which means they were taken directly from the transcripts. A code book was created in an Excel spreadsheet to input ideas and initial codes.

In the Axial coding phase (Neuman, 2006), the researcher read over initial themes carefully in an attempt to condense the data. The researcher looked for themes or categories that clustered together, then grouped them or further subdivided them (Neuman, 2006). This phase refocused the analysis on the broad themes that came from topics identified in the literature and collated relevant coded extracts within the themes (Braun \& Clarke, 2006). This iterative process occurred throughout the analysis as themes were related back to the entire data set and read to see if they accurately reflected the appropriate meanings intended (Braun \& Clarke, 2006). Data within the themes fit together meaningfully and clear and identifiable distinctions were evident across themes (Braun \& Clarke, 2006). 
The final phase involved defining and naming themes (Braun \& Clarke, 2006). At this point, it was clear which aspects of the data each theme captured. Four themes came from the topics identified in the literature, which influenced the research questions. Several subthemes emerged during data analysis and are discussed in detail in the findings chapter. Comparisons are also made with interview and questionnaire data and are presented in the discussion chapter. The final phase of the analysis involved the researcher comparing the subthemes back to the literature to see if there were similarities and/or differences and to the research questions that drove the study. These comparisons are also examined in the discussion section of the project.

The following chapter presents the findings of the research study and provides verbatim quotations from participant responses that capture the themes, which are outlined. Four major themes came from topics identified in the literature and several subthemes are presented that emerged during data analysis. 


\section{Chapter 4}

\section{Findings}

The thematic analysis yielded four major themes and several subthemes. The four main themes are: 1) Early Childhood Educators' Perceptions of Inclusion; 2) Knowledge and Understanding of Individual Program Plans; 3) Training on Inclusive Education; and, 4) Support Needs for Inclusive Education. Each of the four themes is presented separately and account for experiences from all participants in the sample. Perceptions held by early childhood educators and managers are outlined in a comparative format; similarities and differences are discussed for each theme. In addition, group results from questionnaire data are also presented and comparisons are made between interview and questionnaire data in the discussion section. Results are reported as accurately as possible with verbatim quotations used throughout, except where they are altered slightly for readability. This section begins with participant characteristics as they are important context for the research findings.

\section{Participant characteristics}

Fifteen frontline staff and five managers made up the sample for the current research project $(n=20)$. All twenty participants are early childhood educators who are registered with the College of Early Childhood Educators. Of the total sample, 6 participants have been working in the field for more than ten years and 7 participants have been in the field for over twenty years. Therefore, the majority of the participants $(n=13)$ have been working in the field of early childhood education for a significant period of time. In terms of the participants' level of education, 17 participants have a College diploma in Early Childhood Education from an accredited College in Ontario and 6 participants have a university degree in Early Childhood Education or a related discipline from an accredited University in Ontario. All five managers and two of the fifteen frontline staff have taken the daycare management course from a local College 
in Toronto, Ontario. Furthermore, thirteen of the twenty participants stated that they have taken professional development courses or workshops that are relevant to them working with children with special needs in the last three years (additional information about participant characteristics is presented in Table 1, Appendix F).

Experience with disability. The purpose of this study was to gain insight into early childhood educators' perceptions towards inclusion by interviewing educators who have worked with children with disabilities in early learning environments. Educators were purposefully selected who have worked with or who are working with children who have disabilities in child care. Participants were asked about their experiences with disability both professionally and personally. Participants described having worked with children with disabilities that can be classified as congenital, cognitive, neurological, physical and social/emotional. Some examples include spina bifida, speech and language delays, attention deficit hyperactive disorder (ADHD), down syndrome, cerebral palsy, sensory perception disorders, and autism spectrum disorder. Several participants have also worked with children who are not yet diagnosed but are suspected of having a disability. In addition, some of the participants have family members who are currently living with a disability which may have informed their beliefs and attitudes about working with children with disabilities. Of the nine participants who have children of their own, three participants have a child with a disability.

\section{Questionnaire Results}

Questionnaire results were anonymized and cannot therefore be linked to individual participants in the study. Results for the two questionnaires are presented separately and comparisons are made in the discussion chapter. Questionnaire data provide details and group information that are not available from the interview data. 
Efficacy scale. The self-efficacy data show that educators are confident in their ability to modify activities to meet individual needs but that some educators are uncertain about how to help children who are not grasping certain concepts to succeed. All of the 20 participants (strongly agree to slightly agree, $\mathrm{n}=20$ ) felt that they could accurately assess if activities were developmentally appropriate for individual children (see Table 2 for the items and full results of the self-efficacy questionnaire). Furthermore, the majority of the educators (strongly agree or moderately agree, $\mathrm{n}=17$ ) indicated that they are confident in their ability to make modifications to activities to adjust to the child's level. In addition, 19 participants agreed (strongly agree to slightly agree, $\mathrm{n}=19$ ) with the statement If a child in my room becomes disruptive and noisy, I feel assured that I know some techniques to redirect him/her quickly, which suggests that educators are also confident in their behaviour modification strategies. These findings suggest that educators are confident in being able to assess if activities are developmentally appropriate, also in making modifications to meet individual needs, and in their abilities to redirect children with behaviour modification strategies. 
Table 2

Self-Efficacy Scale Results

\begin{tabular}{|c|c|c|c|c|c|c|c|}
\hline & & $\begin{array}{l}\text { Strongly } \\
\text { disagree }\end{array}$ & $\begin{array}{l}\text { Moderately } \\
\text { disagree }\end{array}$ & $\begin{array}{l}\text { Disagree } \\
\text { slightly } \\
\text { more than } \\
\text { agree }\end{array}$ & $\begin{array}{l}\text { Agree } \\
\text { slightly } \\
\text { more than } \\
\text { disagree }\end{array}$ & $\begin{array}{l}\text { Moderately } \\
\text { agree }\end{array}$ & $\begin{array}{c}\text { Strongly } \\
\text { agree }\end{array}$ \\
\hline 1 & $\begin{array}{l}\text { When a child does better than usual, many } \\
\text { times it is because I exerted a little extra effort. }\end{array}$ & & & 2 & 9 & 2 & 7 \\
\hline 2 & $\begin{array}{l}\text { The hours in my room have little influence on } \\
\text { children compared to the influence of their } \\
\text { home environment. }\end{array}$ & 9 & 9 & & 1 & & 1 \\
\hline 3 & $\begin{array}{l}\text { The amount that a child can learn is primarily } \\
\text { related to family background. }\end{array}$ & 6 & 6 & & 4 & 3 & 1 \\
\hline 4 & $\begin{array}{l}\text { If children are not disciplined at home, they are } \\
\text { not likely to accept any discipline. }\end{array}$ & 8 & 5 & 4 & 1 & 2 & \\
\hline 5 & $\begin{array}{l}\text { When a child is having difficulty with an } \\
\text { activity, I am usually able to adjust it to his/her } \\
\text { level. }\end{array}$ & & & 2 & 1 & 5 & 12 \\
\hline 6 & $\begin{array}{l}\text { When a child does something better than } \\
\text { he/she usually does, it is usually because I } \\
\text { found better ways of modeling it for that child. }\end{array}$ & & & 3 & 2 & 10 & 5 \\
\hline 7 & $\begin{array}{l}\text { When I really try, I can get through to most } \\
\text { difficult children. }\end{array}$ & 1 & 2 & 1 & 3 & 6 & 7 \\
\hline 8 & $\begin{array}{l}\text { An ECE is very limited in what he/she can } \\
\text { achieve because children's home environment } \\
\text { is a large influence on his/her achievement. }\end{array}$ & 5 & 9 & 3 & 1 & 1 & 1 \\
\hline 9 & $\begin{array}{l}\text { If a child masters a new concept quickly, this } \\
\text { might be because I know the necessary steps in } \\
\text { teaching that concept. }\end{array}$ & 2 & 2 & 2 & 3 & 7 & 4 \\
\hline 10 & $\begin{array}{l}\text { If parents would do more with their children, I } \\
\text { could do more. }\end{array}$ & 4 & 7 & 2 & 3 & 1 & 1 \\
\hline 11 & $\begin{array}{l}\text { If a child did not remember information I gave } \\
\text { in a previous activity, I would know how to } \\
\text { increase his/her retention in the next activity. }\end{array}$ & 1 & 2 & 3 & 4 & 4 & 5 \\
\hline 12 & $\begin{array}{l}\text { If a child in my room becomes disruptive and } \\
\text { noisy, I feel assured that I know some } \\
\text { techniques to redirect him/her quickly. }\end{array}$ & & 1 & & 3 & 5 & 11 \\
\hline 13 & $\begin{array}{l}\text { The influence of a child's home experiences } \\
\text { can be overcome by good teaching. }\end{array}$ & & 3 & 4 & 5 & 1 & 6 \\
\hline 14 & $\begin{array}{l}\text { If one of the children could not do a class } \\
\text { activity, I would be able to accurately assess } \\
\text { whether the activity was at the correct level of } \\
\text { difficultly. }\end{array}$ & & & & 5 & 7 & 8 \\
\hline 15 & $\begin{array}{l}\text { Even an ECE with good teaching abilities may } \\
\text { not reach many children. }\end{array}$ & 1 & 6 & 1 & 4 & 2 & 4 \\
\hline
\end{tabular}


Results further indicate that there is variance in educators' self-efficacy when it comes to their teaching abilities. For the statement If a child masters a new concept quickly, this might be because I know the necessary steps in teaching that concept, there was a range in participant scores. Six participants (strongly disagree to slightly disagree, $n=6$ ) felt that they did not know the necessary steps associated with teaching new concepts. Although, the majority of participants (strongly agree or slightly agree, $n=14$ ) felt they did know the necessary steps. In addition, 4 educators disagreed with the statement When I really try, I can get through to most difficult children. While 16 of the educators stated that they could support the "most difficult children" (strongly agree to slightly agree, $\mathrm{n}=16$ ), the fact that 4 did not (strongly disagree to slightly disagree, $n=4$ ) indicates that there is variability in the degree of confidence that educators experience.

Similarly, 6 participants (strongly disagree to slightly disagree, $n=6$ ) believe that they would not be able to increase a child's retention in another activity if the child could not remember previous information. This suggests that variations exist in the types of strategies educators use when teaching. Results are consistent with educators' statements in the interviews about not having the appropriate strategies available to help children with special needs succeed in the program. Findings indicate that some educators have lower self-efficacy when it comes to their ability to help a child succeed to a more challenging task. Also, more than half of the participants agreed (strongly agree to slightly agree, $n=10$ ) that even good teaching abilities may not reach many children. Therefore, the participants believe it takes more than teaching abilities to reach children with a range of abilities.

Self-efficacy scale results suggest that educators are confident in their behaviour modification strategies and their ability to modify activities to meet individual needs; however, 
variation exists when it comes to teaching strategies, which suggests that some educators have lower self-efficacy when it comes to their beliefs about their practice.

Disability and education questionnaire. The disability and education questionnaire data indicate that the majority of the sample have positive beliefs about including children with disabilities in their classrooms. Results also suggest that educators are aware that children with disabilities do not receive equal opportunities; 14 of the participants disagreed with the statement Children with disabilities receive equal opportunities in terms of education. Furthermore, the disability and education questionnaire yielded interesting results when participants were asked to score if children with certain disabilities should attend the same child care centres as children without disabilities. While the majority of participants indicated that they believe that children with all diagnostic categories (mental health difficulties, intellectual or learning disabilities, physical disabilities and visual or hearing disabilities) should attend the same child care centre, four participants disagree (strongly disagree to disagree, $n=4$ ) with having children with mental health difficulties in the same centre; three participants disagree (strongly disagree to agree, $n=3$ ) with having children with visual or hearing disabilities in the same centre; and two participants disagree (disagree, $n=2$ ) with having children with physical disabilities in the same centre as non-disabled children (see Table 3 for the items and full results of the disability and education questionnaire).

Table 3

Disability and Education Questionnaire Results

\begin{tabular}{|c|c|c|c|}
\hline & Yes & No & $\begin{array}{c}\text { No } \\
\text { children }\end{array}$ \\
\hline Do you have any children of your own with a disability? & 3 & 6 & 11 \\
\hline
\end{tabular}




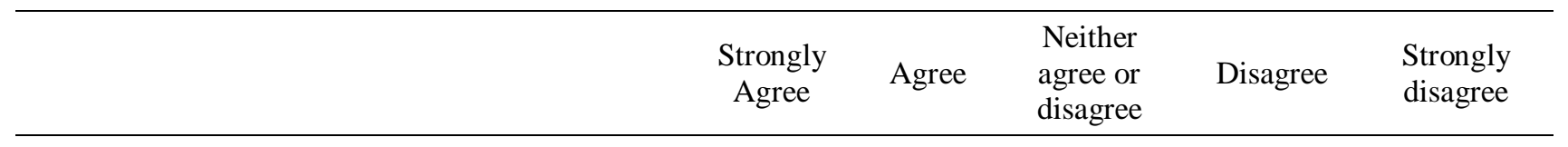

Do you agree or disagree that children with the following disabilities should attend the same centres as children without disabilities?

Mental health difficulties

Intellectual or learning disabilities

Physical disabilities

Visual or hearing disabilities
4

11

11

12

11
6
6
4

2

2

3

12

12

1

In general, do you think that children with disabilities receive equal opportunities in terms of education?

In general, would you object or not if children with the following disabilities were in the same class as your child?

Mental health difficulties

2

Intellectual or learning disabilities

$1 \quad 19$

Physical disabilities

$1 \quad 19$

Visual or hearing disabilities

\section{IF YES TO ANY PART OF Q4, PLEASE ANSWER THE FOLLOWING QUESTION:}

Why would you object if children with disabilities were in the same class as your child (children)?

Special needs considerations:

Facilities in the study area, need special medication

Require facilities, equipment to assist

Require special care

Safety considerations:

Worries about infection

Worries about tendency towards aggression

Possibilities of sudden relapse

Progress of children without disabilities hindered

Progress of children with disabilities hindered

Appearance

Mobility Difficulties

Mental or Emotional Reasons:

Poor mental health

Emotionally unstable

More irritable

Other, please specify: 
More specifically, participants were asked to score whether they would object to having children with the above stated categories of disability in the same room as their own child. Five participants were unsure or would not be comfortable having a child with a mental health difficulty in their own child's class (don't know, $n=3$; I would object, $n=2)$. One participant $(n=1)$ would object to having a child with an intellectual or learning disability in the same class as their own child; one participant $(n=1)$ would object to having a child with a physical disability in the same class as their own child; and one participant $(n=1)$ would object to having a child with a visual or hearing disability in the same class as their own child. It can be suggested that some of the participants in the current study have categorical prejudice towards particular disabilities identified in the questionnaire. Four individual participants displayed prejudice towards three of the categories of disability described in the questionnaire.

If participants indicated that they would object to having a child with a disability in the same room as their own child, they were asked to answer an additional question stating why they would object. Five reasons were stated: 1) facilities and medication, n=1;2) require special care, $\mathrm{n}=2 ; 3$ ) worries about tendency towards aggression, $\mathrm{n}=1 ; 4)$ possibilities of sudden relapse, $\mathrm{n}=1$; and, 5) emotionally unstable, $n=2$. Most of the reasons stated above were raised during the interview process. However, none of the participants raised mental or emotional health reasons when asked if there were children with certain disabilities that could not be included in early childhood settings during interviews. This is interesting because on the disability and education questionnaire, two individuals indicated that mental or emotional reasons were explanations as to why they would not include a child.

In summary, efficacy scale results show that educators are confident with making modifications to meet children's developmental needs and with their behaviour modification 
strategies. However, the findings also suggest that there is variability in the degree of confidence educators have in supporting the "most difficult children". In addition, some educators felt that they would not be able to help children succeed to more difficult tasks and more than half of the participants believe that it takes more than teaching abilities to reach children with different abilities. The disability and education questionnaire results show that most educators have positive beliefs about the placement of children with disabilities with their non-disabled peers. Data revealed that some educators in the sample display categorical prejudice towards some of the disabilities identified in the disability and education questionnaire.

\section{Interview findings}

The following major themes came from topics identified in the literature that were elicited through the interview questions:1) Early childhood educators perceptions of inclusion; 2) Knowledge and understanding of Individual Program Plans; 3) Training on inclusive education; and, 4) Support needs for inclusive education. In addition, several subthemes emerged from analysis of the interview audio recordings and are discussed in their respected categories.

\section{Early childhood educators' perceptions of inclusion}

The first theme that was identified in the literature was early childhood educators' perceptions of inclusion. This section discusses how educators conceptualize inclusion and their experiences within the classroom. Several subthemes that emerged are presented which help illustrate educators' perceptions of inclusion and inclusive practices: how early childhood educators define inclusion, theory versus practice, whether or not centres can be inclusive, and what constitutes inclusive practices in early childhood educators' perspectives.

Definition of inclusion. Prior to describing how early childhood educators practice inclusive education, educators were asked to define inclusion in their own words. This section 
describes their views on inclusive education. Participants defined inclusion in several diverse ways and common definitions are presented. Some participants defined inclusion in terms of equal treatment, a few focused on placement, some described it in terms of participation, while others defined it in terms of the environment. One participant in the study was not able to define inclusion, as she stated "I don't know. It's hard. I don't know. I never thought about that". Finally, some participants' definitions overlap between categories and are reflected in the numerical count at the beginning of each subtheme.

\section{Equal treatment.}

Four participants define inclusion with respect to equal treatment. Equal treatment means that all children in the centre and the classroom are treated the same, regardless of (dis)ability. Participant 1 states:

Inclusion to me is that every child in the room is treated equally and with respect. It doesn't matter what delays you have and that no one is labelled. We're all kids [and] that's the story.

Participant 1 indicates that labelling makes it harder to implement equal treatment because the child is identified as being different:

When the children in the classroom start pointing and blaming that kid because they notice they're different, it becomes harder to implement that everyone is equal because that kid is already labelled in the classroom. It's going to be harder for peer relationships. Participant 1's statement indicates a belief that applying a label has consequences for the child with the special need in terms of forming relationships with peers in the classroom because they stand out from the rest of the children in the room.

Participant 9's definition of inclusion also indicates a belief that equal treatment is important: 
Embedding the child into the program without any sort of significant standing out; keeping it so that it doesn't become the defining point for just that child. It's this is my group and these are the children within my group so there is no really point of labelling or making a child stand out. Inclusion to me is just making everyone feel a part of the group. We're all embraced within the care of the environment.

Participant 9 similarly states that children pick up on differences very easily as she states that "children may be aware that there's something different about a child within the program. It's amazing how children tap into that". Participant 9 further talks about how she, as an ECE, has to be sensitive to both children with disabilities and children who are curious about other children. Both of these participants believe that all children should be treated equally in the environment, regardless of (dis)ability and that differences are to be respected within the early childhood centre.

\section{Placement.}

Six participants focused on placement when they were asked to define inclusion. Placement means that children with and without disabilities are educated in the same setting. Participant 10 describes inclusion in this fashion:

I think inclusiveness is all children together as a whole, whether a child has special needs or not...making sure that you're supporting the child that you're going to be working with. Participant 10's main focus was that children are educated together but he also states that they all need to be supported within the environment. Participant 3 describes inclusion in terms of placement as well but also talks about having the child participate in the program:

I would define inclusion as having the child participate in all areas of the program to their best ability within a day care group setting. Whether [inclusion] be labeled normal or not, 
I think inclusion is very important. [It is important] to have children with special needs to work alongside children who don't have special needs.

Participant 3 states that, in her perspective, integrating all children together is important and having them all participate in all aspects of the program is key. Although she thinks inclusion is important, her comment "whether it be labelled normal or not" can be interpreted to mean that she is suggesting inclusion goes against what is normal. This idea suggests that for participant 3, inclusion is contentious.

\section{Participation.}

Four participants describe inclusion as making sure that all children feel like participants in the program. Participation means that all children are taking part in all areas of the program. Participant 15 describes inclusion as more than just integrating children together:

Everybody is included in the classroom and feels like a participant. So not just bringing them into the classroom, but making sure that they're getting a full day and the full program.

Participant 15 goes on to talk about how any child can be an active participant in the program, while providing a specific example where the child is using additional equipment:

I had a child with severe cerebral palsy and we included him completely. We had something to help him stand up so he could participate in some water activities. Participant 11 also talks about participation, but discusses using an individualized approach so that children can be successful:

Inclusion is making sure that everyone can participate. It's differentiated instruction so that children with different abilities, different skills can still participate and be successful. 
A lot of variety in the room and planning based on observations of the children's needs and skills.

Participant 11 refers to planning curriculum based on observations to meet individual needs in the program. These statements suggest that these educators believe inclusion to be more than the placement of children with special needs into the program, but that individual children are benefiting from all aspects of the curriculum.

\section{Environment.}

Six educators described the environment as an important factor when defining inclusion. The environment is the physical space that children are in. Creating an environment that is conducive to the needs of all the children in the program is the focal point of their definitions. Participant 4 defines inclusion as a space that is developmentally appropriate for all children:

Making sure that the environment is set up to include all children of different abilities, ranges, ages [and] making sure that our program is developmentally appropriate for all children involved in the program. That it meets both the group needs and the individual needs of the children in the program.

Participant 4 illustrates that the environment needs to meet both group as well as individual needs, therefore taking a more individualized approach. Participant 6 believes that it is important for children to succeed in the environment:

Setting up an environment that everybody can succeed in. Setting up social situations that all children could be included in. I think activities that are challenging and flexible and accommodating for all types of children. I think and also accepting of all family types and background. 
This participant is looking at inclusion more holistically. Looking at the environment, the activities and making the appropriate accommodations to challenge the child but giving him/her the opportunity to succeed.

Overall, there was no common or singular understanding of the definition of inclusion for the participants in the study. All of these examples illustrate the different ways educators define inclusion and their range of foci, which help them interpret the concept. Some educators' focus is on the child with the disability and making sure they are receiving equal treatment, others are concerned with actual placement of children, some focus on children being active participants, and finally some believe the environment plays a significant role.

\section{Theory versus practice.}

Several participants said the theory of inclusion was not always feasible within early childhood settings. For example, Participant 1 states that hearing about special needs and working with children with special needs are two completely different things:

[You need to have that] feel [of] working with [children with special needs] instead of just hearing about it. [It] is completely two different stories. I don't feel I was prepared enough to deal with kids with special needs as much as I wanted to be from just [my education].

Participant 1 suggests that there are differences between the understandings of working with children who have special needs versus actually working with children with special needs. Participant 11 says that hands on experience is fundamental to practice:

Reading it is one thing and imaginary scenarios are one thing, but actually having a child with a special need is very different, so I think yeah the hands-on experience is probably beneficial. 
This participant later reveals that had she not completed a speciality placement she would not have been prepared:

I did a speciality placement [with children with special needs] so I got a little bit of extra experience than other students but I don't feel that I would be completely prepared to deal with a child who has a special need.

Participant 11 credits some of her knowledge to an additional qualification course she took entitled Special Education Part 1. According to the Elementary Teachers' Federation of Ontario (2012) Special Education Part 1 is a course that is designed to provide information within the context of Special Education in Ontario, focusing on different special needs as identified by the Ministry of Education. This course can only be taken by individuals who are registered with the Ontario College of Teachers. Participant 11 states:

[Having taken] Part One I'm a little more confident but not a great deal. I feel like I probably should take special education number 2 and 3 before I would be able to work in a special needs classroom.

This participant is a trained and qualified teacher who has received a Bachelor of Education and her conception of inclusion may be influenced by the special education model in schools. Participant 13 believes that through experience one learns how to apply theory:

I mean there's only so much you can learn from a book. There's theory right but when you get out into the real world, that's when you start to say okay you know what yes I can apply this to this situation but it's through experience that you learn and better yourself. This participant is attributing her ability to teach in an inclusive classroom to her experience working with children with special needs. The theory she learned in school was foundational but through experience she became a better early childhood educator. 
Two of the managers hold similar beliefs. Manager 5's statement claims that it is not until an ECE works with children with special needs in the environment that they can identify that they lack experience. Manager 5 states that "resources from the library can help staff but teachers need to live through it first before they actually can say I am inexperienced in this area". Manager 4 similarly explains that "it's one thing reading about children with special needs and diversity and inclusion but it's another doing it". Providing a specific example, Manager 4 exclaims that "[students] come in with all these ideas and then our [child who has a special need] walks in off the bus and you can see the fear in the student's eyes". This manager is suggesting that educators in training are faced with the juxtaposition of theory versus practice during placements.

These participants state that experience working with children with special needs helps prepare educators for the field because understanding theory can be different from actual practice. Participants further identify the importance of experience for novice educators.

\section{Can programs be inclusive?}

Participants state both positive and negative attitudes towards including children with special needs in early childhood settings. Participants were asked whether or not child care centres could be inclusive for all children and four primary considerations emerged from their responses: depending on funding, facility, severity of need, and staff training.

Manager 1 set the tone for the majority of responses:

Child care is such a split up organization that there is no uniform reality to the whole child care industry. [From] center to center it's different, building sites are different, training levels are different, how staff are paid are different, resource availability is different, and that's a problem because than you will not have a standard across the board 
to accommodate children with special needs. I think until you can address some of those concerns of a more universal type programming than forever we will have this diverse type of service for these children with special needs. It will be different from place to place

\section{Funding.}

Funding emerged as a subtheme when educators were asked if centres can be inclusive of all children. Several participants agree that there needs to be more funding to create inclusive environments so that all children can be included. For example, Participant 1 states:

It depends on the funds. Some schools can't afford a flat room. Some schools can't afford elevators. It really depends on the funding and the location of the centre because even though I think they should be, not every school can have children in wheelchairs because there are no elevators for them to go up. It's possible if you have the funds. It's all about the money.

Participant 1 believes that more funding is needed to make appropriate changes in the facility so that it is accessible for all children. In a similar statement, Participant 7 says that funding is important to purchase adaptive materials for children and provides a specific example to illustrate why centres need more funding:

Particularly when you are working with children with special needs because like I said you might have to have adaptive materials in the room to support the developmental level of a child and if you don't have the money than it can be really challenging to support the needs of a child.

These participants suggest that funding is necessary in order for the centre to be accessible to everyone and also to purchase adaptive materials and equipment to support diverse 
needs. Therefore, more funding should be provided to allocate to the restructuring of child care centres along with for buying appropriate equipment.

\section{Facility.}

Many educators describe the facility as a barrier to being inclusive of all children. Participant 2 explains, "I think that if we had the proper facilities and the proper room space I think that we could have everybody, but we'd also need to have assistance". This participant believes that the facility is the starting point but that additional help is also necessary. In a similar position, Manager 2 states, "I think, the expectation is that we should be. I don't think that necessarily every center is setup to be inclusive".

Participant 13 held a more negative belief, "I think sometimes there are certain things that a centre has to realize that they're just not capable of supporting" when it comes to specific disabilities. She goes on to say that supervisors need to be transparent with parents, especially when a child has a physical disability:

[When] supervisors are giving tours to parents. I think this is something that they really should state to parents. If there's ever a fire drill or a fire in the centre they have to keep in mind that we're taking a risk holding their child and carrying him down the stairs. Participant 7 explains that she has worked with many children in the program who were not verbal, who could not walk, who used feeding tubes and many other types of disabilities but finally she states:

I've worked with a lot of different needs with children but I do think there has to be a bit of a cut off when it comes to what's best for that child and the environment they should be in. If they are not getting the proper care that they need and maybe need to be in a 
small class environment with more support... It may not be best for the larger group if there's potential that people can be harmed.

Participant 7 thinks that individual needs have to be assessed in order to determine if group care is the most appropriate place for a child who has a disability. These participants state that the facility may not always be set up to be inclusive for all children and therefore acts as a barrier for some children with disabilities who want to join the program.

\section{Severity of need.}

A number of participants state that some centres cannot be inclusive if the disability is too severe. For example, when asked if a centre can be inclusive for all children, Participant 3 states "I guess it would depend on their individual needs and the severity of children with special needs. If they need specialized care than probably not". In a similar tone, Participant 13 explains: When you have a child who has a physical disability that really becomes a health and safety issue for the child and for the staff so I think we really have to be realistic in the sense that no I don't think sometimes we can be inclusive of every child with every disability. It may not be the politically correct answer but I think that's the way you have to look at it especially as a parent.

Prior to giving this response the participant asked whether or not she could be honest, therefore she felt uneasy responding truthfully. This is also reflected in her final thought stating that 'it may not be the politically correct answer'. Participant 12 expresses a negative belief towards including a child who was Deaf in her program:

If somebody is Deaf or the person is mute, like has no language ability whatsoever for our situation, I don't think that would be one aspect that can be included here because of course we would not understand. 
She further elaborates:

I don't think we have the facilities here to meet those needs so for example, to be honest a child comes in and if she communicates through sign language, I wouldn't be able to meet that need because I don't know sign language so it may be exclusive of somebody who is deaf or somebody who communicates by sign language.

Two managers discuss severity of need as a factor in determining the feasibility of inclusion. Manager 2 states, "depending on the number of children that we have in the program unfortunately if there were more than three in a room than we may have to turn somebody away depending on the level of the need". However, Manager 5 had a previous experience that affected her beliefs about including children with special needs in the centre. When she was a frontline staff, her manager turned away a child with a special need because she didn't think that the staff could handle it. This affected her, as her response explains:

I vowed never to be a manager that ever turns children away that we can help. Whether they're autistic, or they have ADD or ADHD or they have failure to thrive or high anxiety... I felt so defeated and I felt like how dare you assume that I can't help this child. It takes a team right and part of it is you helping me, part of it is us seeking resources and getting our teachers together in on this and I felt that I would never make anybody feel that way.

These participants believe that the severity of the disability is a significant factor in determining whether or not a child can be included in child care or if alternate environments are more suitable to meeting their needs. 


\section{Staff training.}

Several participants refer to staff training as being a barrier to inclusive classrooms.

Participant 5 expresses mixed feelings and suggests that specialized training would be beneficial.

She raises several concerns that are impeding her ability as an educator to be inclusive which include training, time, and the specific needs of the child:

[For some children] group care isn't the best fit. There are times when children need more and depending on what the special need is, some really more intense [care] and a smaller class size and people who specialize in [the disability]. I worked with a child who was really high on the Autism Spectrum and for me it was a really big challenge because I'm not trained in special needs.

She further explains how dividing her time is an additional challenge:

I also have a group of seven other children so my challenge is dividing my time up because sometimes that child needed so much of my attention that it was really hard in sort of this group care setting. So I think that my practice is that 'yes' I think that everyone should be included, but I think if there's some particular child who has been in that setting and needs something beyond what I can do and provide, I think that there might be times where they might need a more intense or specific classroom or facility.

In a similar statement, Manager 1 states:

There are definitely specific needs that are medically addressed that require more training that an ECE would have to receive if [the child] needs more medical treatment than just being a part of a daycare. For example, I don't think daycares can meet the needs of every single child with special needs. 
For Manager 1, some medical needs require more training beyond what early childhood educators can do and therefore child care may not be the most appropriate for some children because medical instruction is not part of typical training programs for early childhood educators.

\section{What constitutes inclusive practices.}

Without specifically asking educators what constitute inclusive classrooms, educators describe, in many different ways, what inclusive classrooms look like in their perspectives. At the very surface level, inclusion for some means representation; others attribute inclusion to additional materials that are required; while some educators discuss adaptations that need to be made to accommodate different abilities; and finally, some educators talk about the actual setup in the environment and the programming.

\section{Materials and equipment.}

Nine participants made reference to materials that are representative of people with disabilities. Participant 3 describes using representation as a means of making her room inclusive for all children:

We have toys that depict children and adults with special needs, more of the visual special needs like walkers and wheelchairs. We have puppets that depict different abilities. We have posters and pictures as well as literature and books.

Participant 3 suggests that having materials in the room that depict individuals with different disabilities is being inclusive of children with special needs. In a similar position, Participant 7 states:

Pictures of people with different disabilities. We have dolls that depict people with different disabilities. We've got a child in our room that wears eyeglasses which isn't 
typical for a child of that age so ensuring that we have a doll in the room that has eyeglasses so that there is a sense of familiarity.

Manager 3 shares a similar perspective, as she states "we do have pictures up. We also have in the drama center there is disabled people toys. Kids in wheelchairs. We have a toy dog for the blind. There's books and dolls". All of these individuals are discussing materials that represent people with different abilities but do not necessarily state how these materials help include children with disabilities in early childhood settings.

Some participants describe materials that are used to meet the needs of individual children in the classroom. For example, Participant 7 describes having materials for a variety of different levels:

Some puzzles we might have for children who are still working with their motor skills with big knobs that are really big pieces and then in some areas we might have more complex floor puzzles for some children.

For Participant 7, having a variety of toys accessible helps meet individual needs within the classroom. Participant 13 provides a specific example of how she would accommodate a child with a special need in her classroom:

We have a child who has a difficult time grasping an object. I wouldn't necessarily put out the thinnest paintbrush, I would put out a chubby paintbrush. Let's go from there so that child then is able to get a better grasp on that chubby paintbrush. [When] I see that he has done really well with that paintbrush, I can then move onto a thinner paintbrush, but not the thinnest paintbrush that we have and go from there and then see how that progresses and then [assessing] if it's working like are the tools that I've taken out working for this child or not. 
Participant 5 describes an adaptive material that is placed on a chair to help the child sit to meet health and safety standards:

we're getting an air filled kind of seat where he is able to rock back and forth and he still has that motion but he's still able to sit. So that's something that we're getting and the bean bag chairs and the fidgety toys... and a weighted snake which helps him regulate. Participant 5 provides examples of some of the materials that are used for this specific child to meet his individual needs within the program. Manager 2 discusses how she supports educators in making sure the program is being inclusive of all children:

We review the materials. We look at the needs of the children that are in the program then we look at the materials that we have. We make sure the environment is friendly for all and if necessary, we will adapt materials that we already have in the space and purchase others to bring in.

\section{Environment and programming.}

Some educators express the necessity to make appropriate changes in the environment on a regular basis and to program according to the needs of the group of children. For example, Participant 5 states:

Adapting our program. Group times were really hard for that child. Group times are now optional where you don't have to [participate]. If sitting for that period of time is too hard than there's other options other than group time and it's for every child. It's not just for that particular child.

Participant 5 describes the process of making adaptations in programming that specifically meet the needs of the child with the disability but that apply to everyone in the program. Participant 4 
states that looking at both the environment and programming is very important in order to meet individual needs:

Looking at our environment and our programming to make sure that we're meeting the children's developmental needs and so if a child has a specific challenge or issue than you'd deal with it by looking at your program and adapting it to fit their needs.

She provides a specific example:

We have children in our program who have sensory processing issues so we make sure that there's lots of different activities to meet their needs. If they have really high energy and are bumping into walls because they need that sensory stimulation or are fidgeting with toys then we make sure that we have a play dough station so that they have the ability to go and get their sensory needs met.

Participant 9 explains creating a cozy nook in the environment to meet the needs of a child who had difficulty self-regulating:

All were welcome to go into that space so that it became a part of the environment so that yes the child who required it used it but in some ways the child thrived so much because socially it became a huge social piece as time progressed.

For Participant 9, the cozy nook helped meet the needs of the child both socially and emotionally. Participant 5 describes programming as the key to inclusive programs and working effectively with the floor partner:

I think it starts with our programming. The way that we program around emergent curriculum, having the ability to come off the floor every week and making sure that that's a priority to come off the floor with my room partner to be able to talk about individuals. It's all about sort of that individualized approach. Being within the group in 
the way that our program runs in that sort of split grouping piece really allows us to be able to observe and get to know children within the room and really plan and program based on sort of individual needs.

Manager 4 states that to make sure the centre is inclusive, she plans a meeting with the parents prior to the arrival of a child with a disability and then "we look at what we need to make accommodations in the room, in the physical space, do we need to make accommodations in getting extra support for staff". Manager 1 states that a resource consultant comes in to help make appropriate accommodations to the program:

A [resource] consultant comes in from the [municipality] to meet with the rooms staff and discuss with them modifications they can make to their programs. So this person will talk about lighting, to space setup, to the volume level of things, certain things they can do to accommodate individual needs.

Participant responses as to what inclusive programs look like in their perspectives varied. Programming and the environment were aspects that some educators described as being indicators of inclusive classrooms, while other participants believed that the adaptations to materials and equipment constituted inclusive classrooms.

\section{Knowledge and understanding of Individual Program Plans (IPP)}

Frontline staff were asked if they were familiar with individual program plans (IPPs). All of the participants except one stated that they were familiar with IPPs. Surprisingly, only eight participants said they have used an IPP in the workforce, four of whom said they have not used one in a very long time. Five participants said they completed a practice IPP at school but had not used one in the field. Finally, only two participants have created an IPP for a child at the centre they currently work at. Participants were asked to describe their role and responsibility in 
the IPP process, as IPPs are an important tool that helps educators meet the goals and objectives for children with disabilities in their programs.

\section{Role and responsibility.}

Educators describe having different roles in the Individual Program Plan (IPP) process. Some indicate that they are responsible for making observations, others talk about observing and planning and some participants describe being responsible for implementing the IPPs.

\section{Observing, planning and implementing.}

The majority of educators who have used an IPP in the field state that their primary role is to make observations of the child. For example, Participant 5 states:

Our role is making sure that we're observing and documenting and making sure that we're documenting things over time [to see if] there is a pattern. So our biggest role is being able to observe and then identify [patterns].

Participant 1 provides a similar response:

Well obviously to observe the child more than once [and] write comments like what he likes, what he doesn't like, where he needs the push and then just go from easy steps. I start with very basic ones and slowly build on that.

Participant 13's experiences are very similar, even though she says she has not used an IPP in about a decade:

Observe and then plan accordingly. Focusing on the child's abilities and then programming for what I see as his or her strengths and going from there and then when I see that there is a challenge, how do I help that child overcome that challenge. Participants 2 and 12 talk about having a role in the implementation process of the individual program plan. Participant 2 states: 
[My role] is the implementation [process of the IPP]. A colleague and I try to follow through with what that child needs or the children need for that day or that week until we follow up with [the resource consultant] the next time then we sit down always together and have brief meetings.

Participant 12 states that her role is to act as the facilitator:

My role now is in facilitating in those activities and to follow up with where [the resource consultant] has left off and then thinking [of ways] to increase or to put more challenges for the child. Well I have to do observations on a daily basis too and I'll see where the improvements need to be made and where the challenges can be made too.

Participant 4, who has created an IPP, describes her role as:

I would be responsible for identifying children or make an assessment of children who would benefit from the IPP. [My role] would be around making observations and assessments, designing the curriculum and implementing the curriculum. [Also] developing the short term goals and the long term objectives [for the child].

Several participants describe the individual program plan as being a collaborative process.

Participant 2 explains the importance of working with her room partner and the resource consultant:

We're part of the discussion of what we have observed and then [the resource consultant] comes and observes what we're talking about and we sit down all together. She's giving us suggestions, we have given her suggestions and then she writes down an IPP for us.

In addition, Participant 9 describes working closely with families as an imperative:

Working very closely with the family...get some background information about how things were working at home versus what we were doing at the centre so that we could 
collaborate those ideas together. See what was working and what we could try together and taking it back to the centre.

Participant 1's statement also indicates the importance of family to the process:

I need the family to be part of it especially because kids in school are different than kids at home and the environment is different and sometimes they are capable of doing things they might do at home but they don't do it at school. It's very crucial for me to have a family meeting at the beginning and let them know what we're planning ahead of time. Participant 5 states that involving families is important because consistency between the home and the child care centre are crucial:

It's around consistency and making sure that the family and the centre are working together to make sure that it's consistent for the child. So I think reaching out to the families is also our role to make sure that they're aware of what is happening.

In summary, participants believe it takes a team to create an IPP for a child who has a disability. The entire process (observing, planning and executing) involves several individuals aside from the educator in the room. Participants expressed having different roles in the IPP process, as they discussed being part of different aspects of the process which suggests a lack of consistency in the use of IPPs in childcare settings.

\section{Challenges with IPPs.}

Several challenges with individual program plans were identified during interviews with early childhood educators. The biggest challenge for educators was time: time for creating IPPs, time for implementing IPPs, and time for the other children in the centre. 


\section{Time.}

Participant 2 requires additional time throughout the day to implement the IPPs to alleviate the amount of work for the other staff in the room:

It's the time on the floor to deal with the individual programming that needs to be directed towards specific children. We have on a regular basis quite a busy room, especially in the toddler room, and when we're focusing one-on-one it's hard for the other colleague to be focusing on nine others. We do have resources that come in and they give us great ideas but sometimes implementing those great ideas there are time restraints because other things are happening.

Participant 7 also views time as a barrier because there are other children in the room that require attention as well:

Finding the time in your program: making sure that you're also balancing your time between all of the children. It's really easy to get fixated on a child that needs the most support and then sometimes the children that are doing okay are the ones that kind of fall behind a little bit when you are doing your specific planning for a child.

Manager 1 states that buy-in from educators is a challenge for him as he has staff who have been in the field for a long time:

The biggest challenge is I have a senior team that came from not very much background [on IPPs]. I think the staff team that I have are used to a streamlined setting where children with special needs were streamlined into different programs where children would be placed into different schools if they had ability issues. That has been a challenge. To get buy-in from the team to know that it is a standard that we should be inclusive and changing the mindset. 
Participant 5 explains that the way the IPP is used is challenging for her because it is not very strength based. She states:

I think it's how you use it because I think when we were doing it... it's not as strength based as a lot of the stuff that we use is because ... it's sort of identifying different areas and it was hard like how do you present that to families. It's a really great tool for us to be able to identify and say okay here's the areas that you know that we need to work on and or here's some red flags.

Participant 9 believes that the IPP is biased based on the perceptions of the individual who is writing it:

The whole biased approach. You don't want to come across trying to make an assumption or a diagnosis on your own because that's not what it is anyway but putting it openly without trying to give away what we think we see because we're not the ones to make the assumption.

Manager 2 states that educators are not knowledgeable of IPPs which she sees as a setback. She articulates that there is a "lack of knowledge for educators. If we haven't been trained how to use them, then we are at a loss, so then we end up relying on our resource consultant".

Time for IPPs emerged as the biggest challenge that educators are faced with from their perspective. The findings indicate that educators believe that there is not enough time to create IPPs, to implement them fully within the program and not enough time for other children in the room. Other challenges are related to staff buy-in, the IPP not being strength based and individual bias held by staff in charge of creating the individual program plan. 


\section{Training for inclusive education}

Another theme that was identified in the literature was training for inclusive education. Several subthemes emerged as the researcher wanted to elicit educators' beliefs about their current training and the training needs identified by educators related to working with children with disabilities and are fundamental in early childhood education programs.

\section{Beliefs about training.}

Of the total sample, 13 participants indicate that they need more training; only four educators felt that they were sufficiently trained to work with children with special needs in an early childhood setting; and the majority of participants felt that they were not adequately trained to meet the needs of children with special needs in an early childhood setting. Participant 1 states that she is not qualified to work with children with special needs:

Its challenging. I'm not going to say it's not. I don't have that qualification to actually know what's required. I can do as much research as I want on my own but as a professional I still wouldn't say 'oh ok I think I know, like I'm sure I can help this kid'. Participant 1 displays a lack of confidence in her ability to meet the needs of children with special needs and she is attributing this to her lack of training. Participant 7 feels as though she has lost her training and that she is relying on the resource consultant:

I've totally lost my training. I don't feel like I've kept current with it. I feel like I'm still working with what I knew and trying to keep up with what I see happening in the field and my discussions with the resource consultant and my own personal reading. I have not had any specific training on special needs.

Furthermore, only four participants in the entire sample felt that they were adequately trained to work with children with special needs in an early childhood setting. For example, 
participant 13 states, "I think the education that I received at [university] was good at that point but then the skills that I've developed throughout the years have helped me be a better ECE". Participant 13 further says that working with a team that is supportive makes her feel as though she is trained, but that her experience would be different if she had to work on her own:

On my own I would have to say no but with the support staff I would say yes. The fact that we work as [a team of] three people in a room, yes and that we have resource consultants that come in, yes but if I was having to do it on my own, probably not. No. In a similar statement, Manager 5 attributes her feelings of being adequately prepared to working in a team:

I feel confident only because I am supported by staff who are really great. I mean I don't have a lot of training in disability. I never really furthered it but I'm confident if a teacher has concerns than let's find the appropriate measures to help out. But as far as my [own] training, I should look into furthering the disabilities part.

Manager 3 articulates that when she attended College nearly 20 years ago, the training was more difficult than it is now. She states, "I think my training was pretty much harder than what I'm seeing today. You had a lot more to do, it was more intense". The researcher probed the Manager by asking her if she felt sufficiently trained to work with children with special needs, her response was:

Yeah, because I did some courses so I think I'm pretty much up there. I did an Autism workshop. It was a three day workshop so it was a little bit more intense to help understand the kids and how to deal with them and stuff like that. 
The participants who feel trained associated their preparedness with working in a team environment and one educator attributed her confidence to a specialized training course she attended.

The vast majority of participants stated that they need additional training to increase confidence to work with children who have special needs. For example, Participant 6 states: I think that as far as making them feel included, I certainly can do that. I don't think that as far as certain strategies and/or activities that I would be able to plan for them accordingly. For sure, no.

She further explains that she is faced with a barrier to furthering her own education:

I know there is a special needs course that people can take and its after work but it really isn't inclusive to the staff because if you are a single mom and you are not able to do that continuing-education kind of stuff than you are kind of screwed in furthering your education around special needs.

Participant 9 believes that no educator is ever fully trained because learning is ongoing: Every time I come back onto the subject, I'm like I know this much (showing little with fingers) but I think that no matter how long I'd even be in the field for, I think there would always be a feeling that I only know this much because it's always ongoing. There's always new information, new tools, new strategies coming out. I think I have an understanding but that's just it, an understanding.

Furthermore, Participant 12 states, "I don't think I have enough really focusing on knowing all about special needs and what strategies I can give. There's still more for me to learn because there are lots of things out there that I don't know about". For Participant 12, further training is required to learn about children with special needs and appropriate strategies. 
The majority of participants suggested that additional training is necessary to increase confidence in educators' abilities to work with children with disabilities in early childhood centres, although a few participants $(n=4)$ feel adequately trained.

\section{Training Needs}

A variety of training needs were identified in the data. The most prominent training need that emerged from individual responses was training on specific disorders. Other training needs are also discussed subsequently.

\section{Specific disorders and needs.}

The majority of participants assert that they would like to see more training on specific disorders that are related to the children coming into early childhood centres. Many educators wanted to see more training specifically on Autism Spectrum Disorder (ASD). To illustrate, Participant 2 articulates the need for training on different disorders:

Training on different disorders. I think that if you have a specific child, we need to know exactly what we need for this person. We need to have training. [The manager] tells us our resources. Can we talk to these resource people and I think that's the only way that we can have them develop in the way they should be because I don't know how to guess. I want to know what's going on with their development and what we need to do as a team.

Participant 3 would like to see paid training made available as she says that salaries are not very high to cover the cost of additional training:

If paid training was available to have one person from each centre [to] get some more expert training on behaviour or special needs or any disorders that you know are up and coming like Autism is becoming a really big one. Anything like that would be great. 
Participant 14 claims that the training that is available to early childhood educators is repetitive and she would like to see more choices being offered that specifically focus on children with special needs. She states, "they're all the same. I wish there was more different [types of] workshops. [More training] on special needs so you can say 'yes I'm trained and I can deal with this'". This participant believes that taking more workshops will better prepare her to work with children with special needs.

Several managers also articulate that more training is required on specific disabilities. Manager 1 states that more training needs to be on "awareness of a variety of abilities, disabilities, special needs on our end so we can be supportive of our team". Manager 3 would like to see more training on Autism, as she states "there seems to be a lot of kids with Autism these days so I think I would like to see some more training in that area". Finally, Manager 5 states the need for "a workshop on disabilities, characteristics of different disabilities. Also, a workshop on inclusion and using proper words and how to be inclusive and be respectful".

\section{Other training needs.}

Several other training needs were also identified by participants. For example, Participant

7 explains that she would like to see training on early intervention and effective communication: Sometimes when children come in and we don't know that they have special needs and this develops to us over time. I think that maybe some early intervention workshops would be important like what to look for and what could be red flags and also some training on how to communicate with families around sensitive issues like this.

Participant 12 describes wanting more education on how to create inclusive classrooms because parents rely on the information provided by the staff at the centre: 
I'd like workshops on how you can make it the best inclusive daycare. How we can improve, what can we do, what strategies we can use to help you know facilitate both parent and child. Especially the parents because a lot of them they don't have the time and leave it to us to help them. For now, it's very little we can give them unless the resource consultant comes in. But if we had the workshops and the training that will help us a lot to help ease the situation with the parents.

Participant 15 states that she would like to go to other child care centres that are inclusive:

If we could go to other centres where things are already being done and being able to watch other people already implement them. If we could have a day where I'm not taking time away from my family because at the end of the day I'm a single mom so it's not really an option for me to be doing things on the weekends or after school.

Managers discuss similar training needs with an emphasis placed on ongoing training. Manager 2 says, "I think that rather than just having a quick course on special needs in the college system, I think that it needs to be more detailed and more thorough. I think that there needs to be ongoing training for staff". Ongoing training is necessary because surface level training results in educators not having the adequate skills available to meet diverse needs. One manager suggests having specific training on leadership development. Manager 1 states:

A lot of education is needed from the leadership side of inclusion. How we can be supportive of our team. I think that is another gap in being inclusive and there's not very much time dedicated to us receiving training as well.

\section{Support needs for inclusive education}

Support needs were also a topic identified in the literature and were elicited by the researcher during interviews with participants. Several subthemes emerged as the researcher 
wanted to elicit specific information about educators' beliefs about supports they currently receive and about the supports that they would like to receive to help them be more inclusive of all children in their programs.

\section{Current Supports}

Educators were asked about the resources they currently have in place to support them for inclusive education. The main support that was identified by all participants was the resource consultant. In addition, some educators viewed their manager as being a support as well.

\section{Resource consultant.}

All of the participants referred to the resource consultant as playing a significant role in assisting educators with strategies and resources to meet the needs of children with disabilities in their classrooms. Participant 2 states that the resource consultant helped her become a better educator:

[The resource consultants] helped my colleague and I become, I think, better teachers for the children who need us and for the children who need to be challenged and for the children who need to be focused on and have these IPPs that we can have them excel and be part of this environment.

Participant 5 describes the resource consultant's role as supporting the staff:

[The resource consultant] is a support to us so yes we work directly with the children but she is our biggest support as far as giving us new studies that might have come out or new ideas. I think that she challenges us in those questions. Why are things happening that way? Why is the room set up this way? And then we have to validate and speak to why we're doing something like that and it makes you think or re-think things so I think having somebody who keeps us in check I think too so you don't become too complacent. 
Participant 7 discusses the role of the resource consultant as observing the children on her caseload and assessing the environment:

We do work with a resource consultant who comes in when there are children on her case load that are in our program. She comes to us once every two or three weeks. Really her role is to come in, observe the child she is working with as well as to observe the environment and what happens with the other children in the room.

Participant 7 continues:

Then together we consult [about] where to go from here, what strategies are working, what strategies are not working, has anything changed in the child, can we do anything differently in the environment to support this.

Participant 15 compares the resource consultant at her current workplace to the one from her previous place of employment. The current resource consultant helps her maneuver the program to meet the needs of the children; however, she explains that this is not always the case:

Where I worked before it wasn't like that. We barely saw the [resource consultant], she came in once a year and she gave us a piece of paper and that was horrible because some things never work and if somebody isn't able to bend it and try something else then we were at a standstill sometimes.

These participants view the resource consultants as a support by providing educators with the necessary strategies to enable early childhood educators to make changes in the environment to meet children's needs. Some view the resource consultant as a validation tool as educators need to provide reasoning to support their decisions about specific aspects of programming. 


\section{Manager.}

Some of the participants stated that they see their supervisor/manager as a support for inclusive education. Managers support educators with their decisions to further their education, in purchasing adaptive materials, in promoting the attendance of different workshops and in providing staff with access to resources. Participant 2 states that her manager is open to the idea of her continuing her education:

Our supervisor is always very receptive to us continuing our education in any form.

We've had people come in to help us. We [have] gone to courses outside of our working hours together as a group to try to learn things that are going on out in the field about whether it's inclusion or whether it's about program planning or anything.

Participant 5 feels confident in being able to approach her manager to buy materials that are required to help accommodate children within the program:

I think to some degree our supervisor too is a support too. So if we need additional resources or if we need to buy things than usually she's happy to go and find those things. With a child that's in our room right now around the sensory processing, sitting is a really big challenge so we sort of came up with some ideas but we needed additional resources too and she's going to go and get them for us.

Participant 9 states that her manager encourages staff to take professional development and use resources that are available to staff:

Our supervisor's fantastic in allowing us those opportunities to utilize community agencies or any [professional development] that would pertain to our field or to our age groups. She tends to encourage us to go out and try so we always have that part like process for some professional development. 


\section{Support needs}

Three major support needs emerged during the analysis of the interview data. Educators and managers identified funding, additional staff and resource consultants as necessary supports for inclusive education in early childhood settings.

\section{Funding.}

Several explanations were provided when participants identified funding as being necessary to increase inclusive practices in early childhood settings. For example, Participant 1 claims that there needs to be more money allocated to purchasing materials and for building infrastructure:

Money for example like wherever you work should have the funding to be able to buy inclass materials, playground materials, elevators. You need money for all these changes in the environment.

Participant 14 also agrees that funding is necessary to purchase appropriate equipment:

[Funding] for buying equipment that you need. Sometimes the child needs a special high chair but it costs hundreds of dollars so you end up using a regular chair [that is not appropriate for the child].

Participant 14 would also like to see more funding for resource consultants to reduce waitlists: It's such a long waiting period. They're on a waiting list and it takes almost six [months] to a year, so it's like you're working alone. They're on a waiting list for the speech therapist for months and then a child is already graduated to the preschool room. That's when the help comes but then I missed my chance of working with that professional. So more money [is needed] to have more resource consultants available [to reduce waitlists]. Moreover, Participant 3 states that funding is required for educating staff: 
I would like to see more resource funding and utilize the experts that we have. I'd like the [municipality] to help with the funding but to also help with the education as well. I don't see a lot of special needs training courses out there. So educating people I think is really important to help include children because everyone [is] taught different things and if some people aren't supportive of inclusion then I think training courses and education is key and funding is key for that.

All of the managers stated that more funding was needed to support staff, to access resources, to give staff more time to observe children and for infrastructure remodelling to be able to accommodate diverse needs in childcare centres. Manager 1 states:

I think funding is a huge key component to make it easier for staff to be inclusive of children [with special needs]. Funding comes down to support in the program by [hiring] additional staff, specialized supports, and individuals who can come in and do particular types of exercises with the child or modifications.

Manager 4 states that more funding would allow educators access to more resources:

A lot of the support is based on money that people don't have to be able to access the resources. Whether it be the family that doesn't have the financial resources or the government says you're only allotted this much and that's all you get. So more funding.

Manager 3 would like "more funds [to] allow the staff to spend more time with a particular child and then you would still have coverage to carry on with the balance of the group". Finally, Manager 2 claims that centres need more funding to make them accessible for all children: There has to be more funding that's put forward to support construction of a lot of centers. In older centers there needs to be a retrofit so there has to be some funding of some sort for that to happen. 


\section{Additional staff.}

Educators state that hiring additional early childhood educators to work in the classroom would give full-time staff more opportunity to spend time with children with special needs. Additional staff would cover ratios and implement individual program plans in the classroom. For Participant 13, an additional staff member would be beneficial to allow her to spend more time with children with special needs in the room:

Having an extra half hour because somebody is coming in to cover you makes a huge deal when you can spend it with a child who has a disability. You're only as good as the supports that you have. If you don't have those supports then you really can't meet the needs of some children.

Participant 14 asserts that ratios need to increase when there are children with special needs in the centre so that more time can be spent with children who have special needs:

[There are] fifteen [children] in the [room] and there are three staff. Each staff has five [children] so in each group if you have one [child] with a special need, who's going to think about the other four [children] because if that one child is not sitting down for lunchtime and they don't want to get their diaper changed. I think you're probably going to need [a] little bit more extra help. [We would] probably need another part-time staff to work with that.

Participant 15 states that she would like the support of an additional staff to be able to effectively implement individual program plans:

You can drop off fifty things for me to do [but] it's going to sit in my cupboard if I don't have somebody that can be there implementing it or working with me so it's really a lot about an additional person. 


\section{Resource Consultant.}

Participants indicate that they would like more time allotted to collaborating with resource consultants when they come into the centre. Participant 3 states that she would like to have a resource consultant in the room more often:

We have a community resource agency that comes in. We do get a lot of support from them but I think just resource support like somebody who kind of floats around like the resource teachers in schools. It would be great if we could have something like that for daycares as well and I know we have a representative but they are called only when they are needed.

Participant 4 also states that she would like to see resource consultants more often:

More access to resource consultants who come in more on a regular basis. Maybe having them in the environment a little bit more. Having access to occupational therapists more too but that's all time constraints.

In a similar statement, Manager 4 states that she would like her staff to have more time with the resource consultant:

It would just be nice to have [the resource consultant] for half a day instead of an hour so that they could sit down and support [the staff] and comment on what is going on in the environment, but it all comes down to time and money. Participants acknowledged that, from their perspectives, in order to increase inclusion funding needs to increase, additional staff are required in the classroom, and more time needs to be allocated with resource consultants when they visit centres.

\section{Summary of Findings}


Findings from the self-efficacy questionnaire illustrate that educators are confident in their abilities to make appropriate modifications to activities to meet individual needs but that some educators are uncertain about how to help children who are not grasping certain concepts to succeed. Findings from the disability and education questionnaire indicate that the majority of participants in the sample have positive beliefs about including children with disabilities in the centre. In addition, the majority of the participants in the sample indicated they would not object to having a child with a disability in the same class as their own child. Some categorical prejudice was also evident towards certain disabilities by a few participants.

Major themes came from topics identified in the literature and several subthemes emerged during data analysis. The first theme identified in the literature was Early Childhood Educators' Perceptions of Inclusion. Findings suggest that educators conceptualize inclusion in different ways and that there is no common or singular understanding of inclusion among this group of participants. Results also illustrate that educators enact inclusive education in a variety of ways based on how they understand inclusion. Finally, participants' attitudes and beliefs about inclusion include both positive and negative beliefs when they discuss whether or not programs can be inclusive for all children. The second topic identified in the literature that was elicited through interview questions was Individual Program Plans (IPP). Findings identify that there is a lack of consistency around the usage of IPPs in programs. Some educators describe not having used an IPP in a long time and some participants state not having used an IPP at all in their current workplace. A lack of consistency is also evident in the roles and responsibilities of educators in the IPP process, where educators describe having different roles. Finally, the key barrier that was identified with using IPPs was time: for creating IPPs, for implementing IPPs, and time for the other children within the classroom. 
The third topic identified was Training for Inclusion Education. Results illustrate that the majority of educators do not feel that they are adequately trained to work with children who have disabilities in the classroom. Some of the training needs that emerged were: training on specific disorders, early intervention, effective communication skills, and inclusion. The final topic that was identified was Support Needs for Inclusive Education. Findings demonstrate that educators view the resource consultant and their manager as a support system for practicing inclusive education. However, additional support needs were identified. Educators emphasized that they want: more time spent with the resource consultant, more funding and additional staff in the classroom to be more inclusive of children with disabilities.. 


\section{CHAPTER 5}

\section{Discussion}

As previously stated, this study explores early childhood educators' perceptions, beliefs and attitudes towards inclusion in early childhood settings. Participants expressed their beliefs about inclusion and gave personal examples of how they practice inclusive education. Results of the thematic analysis suggest that opportunities for ongoing training and more access to resources are sought by educators and might increase confidence in their ability to include children with disabilities in their programs. The following discussion relates the key findings back to the literature. Comparisons between questionnaire and interview data are also discussed and recommendations for future research and practice are presented.

\section{Early childhood educators' perceptions of inclusion}

Participants' responses varied in their definition of inclusion. Definitions ranged from: equal treatment of all children in the room, to the physical placement of children with disabilities with their non-disabled peers, to active participation by all, and finally several participants described inclusion in terms of the environment being conducive to meeting individual needs. This finding is consistent with Barton and Armstrong's (2001) view that inclusion can represent a variety of meanings. The lack of a universal definition, however, can be problematic. Avramidis, Bayliss and Burden (2002) state that the concept of inclusion is perplexing as a variety of interpretations and applications of the concept exist. This was true of the current study.

Some of the educators defined inclusion as meaning equal treatment in the room; however, equal treatment is not always fair for all children. Underwood, Valeo and Wood (2012) state that equity means that the outcomes for all children are fair but that treatment may not always be the same. Treating all children the same in the classroom may not constitute inclusive 
practice. Equity for young children can mean access to specialized supports, known as early intervention that positively affects development (Underwood et al., 2012). Early intervention services, as stated previously, are funded through different provincial ministries and administered by many organizations and agencies throughout the province (Underwood \& Killoran, 2009). Early intervention programs are targeted to improve cognitive, emotional and physical development with the purpose of preventing disability (Guralnick, 2011; Odom, Hanson, Blackman \& Kaul, 2003). Every child in the program may not require an early intervention program, but if the idea is that everyone is treated the same than the child who needs more specialized supports may not get the support that he or she requires.

A number of participants defined inclusion as having children with disabilities educated in the same setting as their non-disabled peers. This finding is consistent with Mancini and Layton's (2004) study where they state that "inclusion advocates promote the philosophy that students with disabilities need to spend as much of the day as possible in a general classroom ( $\mathrm{p}$. 32-33). However, inclusion is more complex than placement. D'Alonzo, Giordano and Vanleeuween (1997) argue that inclusion is supported by values that extend beyond placement. Inclusion assumes a philosophy that incorporates a collaborative environment between teams of professionals working together to support all children within the classroom. Inclusion is much more complicated than simply integrating all children together, as scholars have previously argued (Graham \& Slee, 2006). Placing children with disabilities with their typically developing peers is the first step to inclusion; however, it is a very surface level approach to practicing inclusive education.

Participants who defined inclusion in terms of participation and making changes in the environment grasped important facets of inclusion. Participants stressed the importance of 
individualized instruction and setting up the environment in a way to ensure the success of all children. The definitions which were illustrated by some participants closely align with UNESCO's (2005) statement, which defines inclusion as increasing participation and making changes and modifications where necessary. These findings align with Graham and Slee's (2006) conclusion that placement alone does not constitute inclusion, but rather full participation and appropriate modifications are necessary if full inclusion is to be achieved. Participants provided examples of how they encourage participation and changes they have made to the environment to meet individual needs within the program. In this sense, early childhood educators are programming and creating curriculum that reflect the current cohort of children within their group rather than fitting children with diverse needs into a pre-existing program.

Graham and Slee (2006) posit that there are competing discourses in which the meaning and understanding of inclusion differ. This is troubling because an educators' training can impact how they understand inclusion and in turn how they understand inclusion can affect their practice (Ostrosky, Laumann, \& Hsieh, 2006). Therefore, the way early childhood educators enact inclusive practices may vary depending on their understanding of the concept. This was evident in the current study. Depending on how early childhood educator's defined inclusion was how they explained their practices to the researcher. To illustrate, Participant 8 defined inclusion as "making everyone feel welcomed. Having things that everybody is going to be able to use. Having them be represented in one way or another". When asked to give an example of how she makes the room inclusive for all children, she replied, "In our book shelf we have different books with different families, different ethnicities. We have boards up welcoming everybody in different languages". 
Participant 8's definition discusses the importance of children feeling welcomed and having materials accessible to all children and when asked to give an example, her main focus is about representation within the classroom. This educator displayed an understanding of inclusion that encompasses cultural and linguistically diverse children, but leaves out diversity of abilities. This finding is consistent with Perlman, Kankesan and Zhang's (2008) study which found that staff are employing diversity positive toys and materials, which Garcia and Vazquez (1995) found contribute to formation of positive impressions of diversity in young children.

In addition, several participants discussed inclusive practices as incorporating materials that represent different (dis)abilities, such as dolls in wheelchairs, pictures and posters on the wall and books displayed on the bookshelf. Perlman et al. (2008) caution against the use of "superficial or token-type exposure [as it] may serve only to reinforce stereotypes and fail to encourage positive identity development in diverse classroom populations" (p.20). Instead, to facilitate positive attitude formation, Ramsey (1995) recommends assessing existing knowledge and attitudes toward diversity and planning developmentally appropriate activities that support the needs of all children.

\section{Individual Program Plans}

A key finding that emerged from interview data suggests that the majority of participants are not actively using Individual Programs Plans (IPPs) in their current workplace. One manager stated that educators are not knowledgeable in IPPs which she sees as a setback because of the overreliance placed on resource consultants. Most educators take a single course on inclusion in College, but the majority of these courses fail to provide instructional strategies (Kosko \& Wilkins, 2009). One of the participants in the current study suggested that it would be beneficial to offer a professional development course specifically on IPPs to allow educators the 
opportunity to receive appropriate training. Bunch, Finnegan, Humphries, Dore and Dore (2005) underlined the importance of collaboration of all stakeholders if inclusion is to be successful which include staff, supervisors and other professionals. In the present study, the vast majority of participants described experiences where they valued the opportunities to work in collaboration with room partners as well as other professionals, such as resource consultants or speech therapists. This type of collaboration should be taking place when a child with a disability has an individual program plan. An IPP is a tool designed to provide the necessary goals and objectives for the individual child to ensure success in the program; therefore, it is created to ensure that the educator takes the necessary steps to make sure that the child is given equitable opportunities to succeed. Hollingsworth, Able Boone and Crais (2009) emphasize the importance of interdisciplinary collaboration to implement a functional IPP. Managers in the current study were supportive of this idea as they stated that they would like their staff to have more time with resource consultants to work on IPPs. Educators reported being satisfied with the support they received from resource consultants but collectively agreed that they would like more time with them in the program to increase inclusive education. Therefore, the participants do not oppose the idea of collaborating with others; they would prefer it, if it were available as a viable option.

\section{Can programs be inclusive?}

According to participants' responses, programs can be inclusive depending on certain considerations: funding, facility, severity of need, and staff training. Both positive and negative attitudes towards including children with disabilities were evident. Participants' views aligned with both the social and medical model of disability. Educators' beliefs that aligned with the medical model view disability as stemming from individual characteristics or pathologies (Skinner \& Weisner, 2007). This was evident as several participants described not being able to 
include children because of their disabilities. However, according to Ontario Human Rights Code, R.S.O. 1990,c.H.19, section 2(1), every person has a right to accommodation without discrimination because of disability. Brown and Guralnick (2012) argue that in addition, article 23 of the Convention on the Rights of the Child (CRC) states that "children with disabilities have the right to special assistance...taking into account the circumstances of the child and those responsible for his or her care" (p.274). Therefore, it is the centre's duty to accommodate. Educators' beliefs that aligned with the social model recognize that societal barriers are impeding children's access from full participation (Bines \& Lei, 2011). This was also evident as some educators felt that the facility was acting as a barrier from including some children because it was inaccessible. These findings are consistent with Thornton and Underwood's (2012) study which found that different educators held beliefs that aligned with both models of disability. These differences can be attributed to educators experience working in the field and training they receive on inclusion.

In addition, the social model of disability looks at the environment; therefore, educators talk about the environment and not changes to their own behaviours or attitudes would support an inclusive environment. The findings suggest that educators have limits on how they value inclusion as several exceptions were presented to the researcher. Furthermore, there were inconsistencies in their responsibilities within the classroom and their roles in developing and implementing program plans for children with IPPs. Rose (2001) stresses that teachers need to accept the responsibility for the education of all children. This responsibility should not fall onto resource consultants or other professionals, as these supports are in place to act in accordance with classroom practice and should not replace the expectations of the early childhood educator. 
In the end, it is an educator's responsibility to educate children, not the resource consultants' or other professionals' and therefore they need to take ownership and responsibility over their roles.

\section{Training Needs}

The vast majority of participants in the current study stated that they need more training when it comes to working with children with special needs in inclusive classrooms. According to Grace (2013), there is a difference between education and training; however, both present new information to students. Training provides students with more job-specific skills, whereas education provides foundational knowledge. Participants in the current study defined training as consisting of workshops that provide early childhood educators with additional knowledge on particular topics. For example, educators would like workshops on different disabilities, on effective communication and inclusion. These workshops could include an overview of different disabilities, especially those that are more common; specific strategies that enable educators to work with diverse needs; and on inclusion and its effectiveness. Mulvihill, Shearer and Van Horn (2002) found a relationship between disability and inclusion training and attitudes toward inclusion. Participants who participated in specific training reported fewer attitudinal barriers than individuals who did not receive training. Therefore, according to these researchers, training can help combat against prejudicial attitudes held by some educators.

Participants in the current study described wanting to gain skills and therefore training, as opposed to education is recommended. Educators want to receive more training to increase confidence when working with children with diverse needs. This finding is consistent with literature (Bruns \& Mogharreban, 2007; Mancini \& Layton, 2004), which states that additional training is required to effectively work with children with special needs. Mancini and Layton (2004) argue that specialized training is necessary to meet diverse needs and some of the 
participants in the current study stated that they would like to see specialized training on specific disabilities being offered. Baker-Ericzen, Mueggenborg and Shea (2009) examined training and its impact on educators and found that when educators received specialized training, there was a positive shift in their beliefs about inclusion. This finding is also consistent with Mulvihill et al's (2002) study. Some of the participants in the current study who have taken professional development related to working with children with special needs expressed greater competency in their abilities to be inclusive of diverse needs. Additional studies found that educators express more positive attitudes and confidence when provided direct training and education to work with children who have special needs (Hornby, 1999; Leatherman \& Niemeyer, 2005). Although the same conclusions cannot be drawn for current findings, it can be suggested that training may have an impact on level of competency.

Leatherman (2007) found that in inclusive classrooms, educators are more aware of differences between children and can make accommodations so that all children can successfully participate. However, in the current study, some educators expressed concerns with not knowing the appropriate strategies to work with children who have disabilities. Several educators suggested that they are not equipped with the specific skills and strategies that are needed to work with diverse abilities in the classroom. Some educators highlighted the urgency of training that is required in order to avoid guessing what it is the child requires. Specific examples illustrate a necessity for additional training to increase confidence in educators' ability to plan effectively in order to meet all of the diverse needs in the classroom. These findings are consistent with Rose's (2001) study where educators also expressed a need for additional training as they were concerned with their lack of skills. Ainscow (1999) identified experience as an important part of training as it is easier to tailor training needs depending on personal 
circumstances within inclusive environments. The current study's findings provide explicit examples of the type of training that educators believe will increase competency for practicing inclusive education, which include ongoing training on specific disorders and different types of disabilities. Therefore, the intention of specific training is to eradicate attitudinal barriers and increase educators level of competency to include children with disabilities in their programs.

\section{Support Needs}

A variety of support needs emerged from the interviews; however, educators viewed the resource consultant and the manager as the main supports for practicing inclusive education. This is consistent with Lohrmann and Bambara's (2006) research, which found that direct support from administrators was crucial in supporting educators in inclusive programs. Participants from the current study felt that managers were accessible and encouraged staff to seek professional development training and support. This finding is consistent with Horne and Timmons' (2009) results which indicate that educators felt supported when supervisors allocated time for planning and provided appropriate support to staff. Managers, in the current study, indicated that they assist staff where they can by providing more time for planning, purchasing adaptive materials and finding appropriate resources. All of the participants expressed positive attitudes about the support they received from their managers.

All interviewees discussed the importance of support from the resource consultant in enabling inclusion to be successful. Several participants stated that they would like to have the resource consultant spend more time in the classroom assisting educators. One participant in particular stated that she would like to have a permanent resource teacher in the classroom similar to the special education model in the school system. However, Thomas, Walker and Webb (1998) caution that there should be careful consideration to the ways in which additional 
classroom support is utilized. The allocation of additional staff specifically to children with special needs does not support inclusion and may create dependency in the child and emphasize differences of the child with a disability. Results of the current study suggest that educators rely heavily on resource consultants. This could suggest that they have a lower self-efficacy when it comes to the skills they have available to effectively meet individual needs within the classroom. Hunt, Soto, Maier, Liboiron and Bae (2004) emphasized the importance of collaborative planning between educators and support staff to meet the needs of children with disabilities. Regular meetings increased accountability and assisted educators in being consistent with implementing plans. This finding is consistent with educators' reasoning for wanting more time with resource consultants. Participants indicated that more time would increase consistency with the implementation of IPPs and regular meetings would keep educators on track.

\section{Questionnaire and Interview data}

The self-efficacy scale measured educators' beliefs about their perceptions of themselves as educators. The self-efficacy data show that educators are confident in their abilities to make appropriate modifications to activities. This was consistent with interview data as educators provided specific examples of the adaptations they have made to meet individual needs in the classroom, such as modifying in-class equipment or making changes to programming. However, self-efficacy results further suggest a lack of confidence when it comes to educators' abilities to help children succeed to more difficult tasks. This finding suggests that educators have a lower personal teaching efficacy, described by Arceneaux Rheams and Bain's (2005) as an educators' belief in his/her own ability to affect student learning. This finding is supported by educators statements during interviews where some participants indicated not having the appropriate skills necessary for helping children with disabilities succeed. Niemeyer and Proctor (2001) 
interviewed students who were preparing to enter the field of early childhood education and found that while their beliefs about inclusion were positive, they were not confident in their abilities to plan, instruct and manage inclusive programs. Neimeyer and Proctor's study is consistent with the current research findings. Generally, most educators held positive beliefs, but displayed a lack of confidence in using effective strategies when working with children with disabilities.

Erdem and Demirel (2007) argue that individuals judge their abilities according to their behaviour which has a role in understanding self-efficacy. Fourteen of the twenty participants agreed that children with disabilities do not receive equal opportunities in terms of education. This finding is consistent with literature about children with disabilities and education (Barton \& Armstrong, 2001; Killoran, Tymon \& Frempong, 2007). In addition, while most participants were positive about having children with (dis)abilities be educated in the same centres, a few individuals disagreed with having children with mental health difficulties $(n=4)$, physical $(n=2)$ and visual or hearing difficulties $(n=3)$ in the same centre as typically developing children. This finding was also supported during participant interviews. The researcher asked participants if there were certain disabilities that would not allow a child to participant and some individuals' responses were consistent with the categories of disability described above. Interestingly, none of the participants raised mental health difficulties when providing examples during interviews.

While participants identified from most of the categories of disability in the questionnaire and interview data, it can be inferred that there is more stigma associated with mental health difficulties than the other categories illustrated. According to Heflinger and Hinshaw (2010) mental illness is one of the most stigmatized illnesses in current society. Stigmatization is also seen as a significant barrier to service access and utilization (Thorncroft, 2006). Professional 
stigma includes attitudes and practices that can affect children's learning because lower expectations are placed on the child (Heflinger \& Hinshaw, 2010). Moreover, Pescsolido, Jensen, Martin, Perry, Olafsdottir and Fettes (2008) found that people discriminate between different types of disabilities and rank them by level of severity. Although the current study cannot be generalized beyond the scope of the sample, some educators' beliefs confirm existing research.

\section{Limitations}

The use of convenience sampling resulted in a small group of participants who were from a limited number of settings. Neuman (2006) argues that a limitation to convenience sampling is that it can be highly unrepresentative of the population. Due to the small sample size, findings cannot be generalized beyond the group of early childhood educators in the study; however, results are consistent with previous research which increases the validity of the current study's findings. Gibbs (2007) argues that the intention is not to generalize findings beyond those under study as qualitative research lies in the particular description and themes within a specific context.

Another limitation to the current study is with regard to methodology and the use of selfreported data. According to Gonyea (2005), an issue that threatens the credibility of self-reported data is social desirability bias, where the participant answers in a way to look good in front of the research (Beretvas, Meyers \& Leite, 2002). Social desirability bias is more prevalent in face-toface interviews than in questionnaires (Tourangeau, Rips \& Rasinski, 2000). Gonyea (2005) recommends using multiple data sources or triangulation to increase the trustworthiness of the responses. In the present study, questionnaires were anonymized in order to encourage participants to respond truthfully. 


\section{Future Research}

The results of the current study indicate the need for additional research. A larger sample size is needed to produce more definitive results that can be generalized beyond the scope of this study. In-class observations of classroom practices would provide more information about how educators practice inclusive education in a naturalistic environment. Furthermore, children's perspectives would also be worth investigating in order to gain an understanding of inclusion from their point of view and capture their experiences in inclusive early childhood settings.

\section{Recommendations}

The findings of the current study suggest that on-going professional development is essential for educators to stay current with their training. Explicit skills training that relate to topics of diversity and awareness of disabilities (Odom, 2002), as teachers who are more aware of diversity are more likely to incorporate different teaching methods and create more inclusive classrooms (Perlman, Kankesan \& Zhang, 2008). Training about different diagnostic categories and characteristics of students is desired by most educators in the study, as more children are entering childcare with diverse needs.

The researcher is aware that training may be limited in what it can do to achieve the kind of transformation that Graham and Slee (2006) describe because as much as inclusion is about eliminating barriers that impede access, it is also about changing attitudes and beliefs. Although the majority of participants had positive attitudes, there were some individuals who displayed categorical prejudice towards some disabilities that were identified. Changing the way people think about disability and inclusion are obstacles that many scholars face, but it is through listening to and understanding individual experiences that enable researchers to identify patterns 
and hopefully little by little change attitudes and beliefs through research and by disseminating the knowledge that is obtained.

In addition, it is recommended that a workshop should be provided on effective collaboration for frontline staff, managers and other professionals who are frequenting child care centres. Collaboration workshops can focus on how each professional can contribute to the team to ensure that all children with the centre are getting their needs met and are active participants in the program. It can also focus on time management skills, in order to maximize the time spent with professionals who visit child care centres. Finally, this type of workshop can teach communication skills and current language use so that all parties are familiar with current terminology and best practice. It is also important that individuals have a clear understanding of what their responsibilities and expectations are within the collaborative partnership.

It is also recommended that funding reallocations be made in order for resource consultants to frequent child care centres more regularly and for longer periods of time to effectively collaborate with early childhood educators on a regular basis. Due to a lack of training on working with children with diverse needs, educators in the current study rely on the support from resource consultants to provide recommendations and strategies to assist them when working with children with disabilities. Therefore, either more training needs to be provided for educators to increase competency or more supports need to be readily available to educators within and outside of the classroom. If that cannot be accomplished, there needs to be better time management strategies available to maximize time spent with professionals who visit child care centres and act as supports for staff and children with programs. 


\section{Conclusion}

The results of this study are derived from the perceptions of twenty early childhood educators working in six early childhood centres across Toronto, Ontario. According to the findings, inclusion is a comprehensive concept that is defined using different parameters for each participant. According to Bandura's social cognitive theory, educators' understandings of inclusion, which are informed by their beliefs can influence their practice. Although the researcher did not investigate whether or not the child care centres had a policy on inclusion, it is important to state that early childhood centres should have a policy explicitly stating inclusionary provisions so that educators share a common understanding and commitment to the idea and philosophy of inclusion. Educators in the study held beliefs that align with both the medical and social model which is consistent with previous literature. Outcomes for children are influenced by educators' beliefs, training and supports they receive to practice inclusive education.

"Inclusion should not refer to a place, but should describe an active process that promotes child development by providing services and supports to facilitate participation of all students" (Villeneuve, 2013, p.10). Furthermore, educators' beliefs and practices must be addressed through ongoing training and support to best serve young children with disabilities in early childhood settings. We must consider the following very wisely:

We must also acknowledge and ameliorate the gaps arising from our efforts to include. Fundamentally, we must ask what assumptions might inform our personal and collective philosophies in relation to inclusive education? What do we mean when we talk of including? What happens? Whose interests are being served? And most of all, into what do we seek to include? (Graham \& Slee, 2006, p.20, original emphasis). 


\section{References}

Ainscow, M. (1999). Understanding the Development of Inclusive Schools. London: Falmer.

Allan, J. (2008). Rethinking inclusive education: The philosophies of difference in practice. Dordrecht: Springer.

Allen, K. E., Paasche, C. L., Langford, R., \& Nolan, K. (2011). Inclusion in early childhood programs: Children with exceptionalities (5th Canadian ed.). Toronto, ON: Nelson Education.

Arceneaux Rheams, T. \& Bain, S. K. (2005). Social interaction interventions in an inclusive era: Attitudes of teachers in early childhood self-contained and inclusive settings. Psychology in the Schools, 42(1), 53-63.

Avramidis, E., Bayliss, P. \& Burden, R. (2002) Inclusion in action: an in-depth case study of an effective inclusive secondary school in the south-west of England. International Journal of Inclusive Education, 6(2), 143-163.

Bandura, A. (1986). Social foundations of thought and action: A social cognitive theory. Englewood Cliffs, NJ: Prentice Hall.

Baker-Ericzen, M. J., Mueggenborg, M. G., \& Shea, M. M. (2009). Impact of trainings on child care providers' attitudes and perceived competence toward inclusion: What factors are associated with change? Topics in Early Childhood Special Education, 28(4), 196-208.

Banerji, M. \& Dailey, R. A. (1995). A study of the effects of an inclusion model on students with specific learning disabilities. Journal of Learning Disabilities, 28(8), 511-522.

Barnes, C. \& Mercer, G. (2001). Assimilation or Inclusion? In G. L. Albrecht, K.D. Seelman, \& M. Bury (Eds.) Handbook of Disability Studies. Thousand Oaks: Sage.

Barnes, C., Mercer, G., \& Shakespeare, T. (1999). Exploring disability: A sociological introduction. Malden, MA: Blackwell Publishers Inc. 
Barnes, C., Oliver, M. \& Barton, L. (2002). Introduction. In C. Barnes, M. Oliver \& L. Barton (Eds.) Disability Studies Today. Malden, MA: Blackwell Publishers Inc.

Barton, L. (1997). Inclusive education: Romantic, subversive or realistic? International Journal of Inclusive Education, 1(3), 231-242.

Barton, L. \& Armstrong, F. (2001). Disability, Education and Inclusion: Cross-Cultural Issues and Dilemmas. In G. L. Albrecht, K.D. Seelman, \& M. Bury (Eds.) Handbook of Disability Studies. Thousand Oaks: Sage.

Beretvas, S., Meyers, J., \& Leite, W. (2002). A reliability generalization study of the MarloweCrowne social desirability scale. Educational and Psychological Measurement, $62(4), 570-589$.

Bines, H. \& Lei, P. (2011). Disability and education: The longest road to inclusion. International Journal of Educational Development, 31, 419-424.

Braun, V. \& Clarke, V. (2006). Using thematic analysis in psychology. Qualitative Research in Psychology, 3, 77-101.

Brown, S. E. \& Guralnick, M. J. (2012). International human rights to early intervention for infants and young children with disabilities: Tools for global advocacy. Infants \& Young Children, 25(4), 270-285.

Bruns, D. A. \& Mogharreban, C. C. (2007). The gap between beliefs and practices: Early childhood practitioners' perceptions about inclusion. Journal of Research in Childhood Education, 21(3), 229-241.

Bunch, G., Finnegan, K., Humphries, D., Dore, R., \& Dore, L. (2005). Finding a way through the maze: Crucial terms used in education provision for Canadians with disabilities. Crucial 
terms final report. Toronto, ON: The Marsha Forest Centre. Retrieved from http://www.marshaforest.com/crucialterms.pdf

Canadian Charter of Rights and Freedoms, Part I of the Constitution Act, 1982, being Schedule B to the Canada Act 1982 (UK), 1982, c 11. Retrieved from http://lawslois.justice.gc.ca/eng/Const/page-15.html

College of Early Childhood Educators. (2012). College of Early Childhood Educators. Retrieved from http://www.collegeofece.on.ca/en/AboutUs/Pages/default.aspx

Cole, P. (2007). The body politic: Theorising disability and impairment. Journal of Applied Philosophy, 24(2), 169-176.

Committee on the Rights of the Child. (2006).General Comment No. 9: The rights of children with disabilities. United Nations.

Creswell, J. W. (2009). Research design: Qualitative, quantitative, and mixed methods approaches. (Eds.) Thousand Oaks: Sage Publications Inc.

D'Alonzo, B. J., Giordano, G. \& Vanleeuwen, D. M. (1997). Perceptions by teachers about the benefits and liabilities of inclusion. Preventing School Failure, 42(1), 4-11.

DEC/NAEYC. (2009). Early Childhood Inclusion: A joint position statement of the Division for Early Childhood (DEC) and the National Association for the Education of Young Children (NAEYC). Chapel Hill: The University of North Carolina, FPG Child Development Institute.

Denzin, N. K. (2012). Triangulation 2.0. Journal of Mixed Methods Research, 6(2), 80-88. Elementary Teachers' Federations of Ontario. (2012). Special Education, Part 1. Retrieved from http://etfo-aq.ca/catalogue/special-education-part-1/ 
Erdem, E. \& Demirel, O. (2007). Teacher self-efficacy belief. Social Behavior and Personality, 35(5), 573- 586.

Flick, U. (2007). Designing qualitative research. London, England: SAGE.

Forlin, C. \& Chambers, D. (2011). Teacher preparation for inclusive education: Increasing knowledge but raising concerns. Asia-Pacific Journal of Teacher Education, 39(1), 1732.

Frankel, E. B. (2004). Supporting inclusive care and education for young children with special needs and their families: An international perspective. Childhood Education, 80(6), 310-316.

Garcia, C. T., \& Vazquez, H. A. (1995). Developmental processes and their influence on interethnic and interracial relations. In W. D. Hawley \& A. W. Jackson (Eds.), Toward a Common Destiny (pp. 103-130). San Francisco: Jossey-Bass.

Gibbs, S. (2007). Teachers' perceptions of efficacy: Beliefs that support inclusion or segregation. Educational and Child Psychology, 24(3), 47-53.

Gibson, S. \& Dembo, M. H. (1984). Teacher efficacy: A construct validation. Journal of Educational Psychology, 76(4), 569-582.

Gonyea, R. M. (2005). Self-reported data in institutional research: Review and recommendations. New Directions for Institutional Research, 127, 73-89.

Goodfellow, A. (2012). Looking through the learning disability lens: Inclusive education and the learning disability embodiment. Children's Geographies, 10(1), 67-81.

Grace, L. M. (2013). A more operable definition for training and education. International Journal of Emergency Services, 2(1), 21-28. 
Graham, L. J. \& Slee, R. (2006). Inclusion? Disability Studies in Education Special Interest Group, American Research Association 2006 Annual Conference, San Francisco. Retrieved from http://eprints.qut.edu.au.

Guralnick, M. (2011). Why early intervention works: A systems perspective. Infants \& Young Children, 24(1), 6-28.

Hall, A. H. \& Niemeyer, J. A. (2000). Inclusion of children with special needs in school-age child care programs. Early Childhood Special Education Journal, 27(3), 185-190.

Hammond, H. \& Ingalls, L (2003). Teachers' attitudes toward inclusion: Survey results from elementary school teachers in three southwestern rural school districts. Rural Special Education Quarterly, 22(2), 24-30.

Heflinger, C. A. \& Hinshaw, S. P. (2010). Stigma in child and adolescent mental health services research: Understanding professional and institutional stigmatization of youth with mental health problems and their families. Administration and Policy in Mental Health and Mental Health Services Research, 37(1), 61-70.

Heiman, T. (2004). Teachers coping with changes: Including students with disabilities in mainstream classes: An international view. International Journal of Special Education, 19(2), 91-103

Hollingsworth, H.L., Able Boone, H. \& Crais, E. R. (2009). Individualized Inclusion plans at work in early childhood classrooms. Young Exceptional Children, 13(1), 19-35.

Hornby, G. (1999). Inclusion or delusion: Can one size fit all? Support for Learning, 14(4), 152 157.

Horne, P.E. \& Timmons, V. (2009). Making it work: teachers' perspectives on inclusion. International Journal of Inclusive Education, 13(3), 273-286. 
Hughes, B. (2001). Disability and the body. In G. L. Albrecht, K.D. Seelman, \& M. Bury (Eds.) Handbook of Disability Studies. Thousand Oaks: Sage.

Hunt, P., Soto, G., Maier, J., Liboiron, N. \& Bae, S. (2004). Collaborative teaming to support preschoolers with severe disabilities who are placed in general education early childhood programs. Topics in Early Childhood Special Education, 24(3), 123-142.

Hwang, Y. \& Evans, D. (2011). Attitudes towards inclusion: Gaps between belief and practice. International Journal of Special Education, 26(1), 136-145.

Irwin, S., Lero, D. \& Brophy, K. (2004). Inclusion: The next generation in child care in Canada. Wreck Cove, NS: Breton Books.

Jordan, A. \& Stanovich, P. (2003). Teachers' personal epistemological beliefs about students with disabilities as indicators of effective teaching practices. Journal of Research in Special Educational Needs, 3(1).

Jordan, A. Glenn, C. \& McGhie-Richmond, D. (2010). The supporting effective teaching (SET) project: The relationship of inclusive teaching practices to teachers' beliefs about disability and ability, and about their roles as teachers. Teaching and Teacher Education, 26, 259-266.

Killoran, I., Tymon, D. \& Frempong, G. (2007). Disabilities and inclusive practices within Toronto preschools. International Journal of Inclusive Education, 11(1), 81-95.

Kohen, D., Dahinten, V. S., Khan, S. \& Hertzman, C. (2008). Child care in Quebec: Access to a universal program. Canadian Journal of Public Health, 99(6), p. 451-455.

Konecki, K. T. (2008). Triangulation and dealing with the realness of qualitative research. Qualitative Sociology Review, 4(3), 7-28. 
Kosko, K. W. \& Wilkins, J.L.M. (2009). General educators' in-service training and their selfperceived ability to adapt instruction for students with IEPs. The Professional Educator, 33(2), 1-11.

Kucuker, S., Acarlar, F. \& Kapci, E. G. (2006). The development and psychometric evaluation of a support scale for pre-school inclusion. Early Child Development and Care, 176(6), 643-659.

Leatherman, (2007). "I just see all children as children": Teachers' perceptions about inclusion. The Qualitative Report, 12(4), 594-611.

Leatherman, J. M., \& Niemeyer, J. A. (2005). Teachers' attitudes toward inclusion: Factors affecting classroom practices. Journal of Early Childhood Teacher Education, 26, 23-36.

Loflan, J., Snow, D., Anderson, L., \& Lofland, L. H. (2006). Analyzing social settings: A guide to qualitative observation and analysis. ( $4^{\text {th }}$ ed.). Belmont, CA: Wadsworth/Thomson Learning.

Lohrmann, S. \& Bambara, L. M. (2006). Elementary education teachers' beliefs about essential supports needed to successfully include students with developmental disabilities who engage in challenging behaviors. Research \& Practice for Persons with Severe Disabilities, 31(2), 157-173.

Mancini, K. G. \& Layton, C. A. (2004). Meeting fears and concerns effectively: The inclusion of early childhood students who are medically fragile. Physical Disabilities: Education and Related Services, 22(2), 29-48.

Marvasti, A. B. (2004). Qualitative research in sociology. London, England: SAGE.

McWilliam, R. A. (2005). DEC recommended practices: Interdisciplinary models. In S. Sandall, M. L. Hemmeter, B. J. Smith, \& M. E. McLean (Eds.), DEC recommended practices: A 
comprehensive guide for practical application in early intervention/early childhood special education (pp. 127-131). Longmont, CO: Sopris West.

Mertens, D. M. \& Hesse-Biber, S. (2012). Triangulation and mixed methods research: Proactive positions. Journal of Mixed Methods Research, 6(2), 75-79.

Morse, J. M. \& Niehaus, L. (2009). Mixed method design: Principles and procedures. Walnut Creek, CA: Left Coast Press, Inc.

Mulder, S. L. (2010). Exploring the relationships between teachers' self-efficacy and teachers' multicultural self-efficacy (Doctoral dissertation, University of Kentucky). Retrieved from http://search.proquest.com.ezproxy.lib.ryerson.ca/docview/919062648

Mulvihill, B., Shearer, D., \& Van Horn, M. L. (2002). Training, experience and child care providers' perceptions of inclusion. Early Childhood Research Quarterly, 17(2), 197-215.

National Disability Authority. (2006). Appendix 3: Questionnaire. Retrieved from http://www.nda.ie/cntmgmtnew.nsf/0/FD9B9DBF1F1CF617802573B8005DDED5/\$File/ drs8_attsurvey_08.htm

Neuman, W. L. (2006). Social research methods: Qualitative and quantitative approaches $\left(5^{\text {th }}\right.$ ed.). Boston, MA: Pearson Education Inc.

Odom, S. (2002). Widening the circle: Including children with disabilities in preschool programs. New York: Teachers College Press.

Odom, S., Hanson, M., Blackman J. \& S. Kaul, S. (Eds). (2003). Early Intervention Practices around the World. Baltimore: Brookes.

Ontario Government. (1990). Days Nurseries Act. R.R.O. 1990, Regulation 262, General. Retrieved from http://www.elaws.gov.on.ca/html/regs/english/elaws_regs_900262 _e.htm 
Ontario Ministry of Education. (2000). Individual education plans: Standards for development, program planning, and implementation. Retrieved from http://www.edu.gov.on.ca/eng/general/elemsec/speced/iep/iep.pdf

Ontario Ministry of Education. (2013). Child care. Retrieved from http://www.edu.gov.on.ca/childcare/index.html

Ontario Human Rights Code. (2009). Guidelines on accessible education. Retrieved from http://www.ohrc.on.ca/sites/default/files/attachments/Guidelines_on_accessible_educatio n.pdf

Ontario Human Rights Code. (2012, c.7). Human Rights Code. R.S.O. 1990, Chapter H.19. Retrieved from http://www.elaws.gov.on.ca/html/statutes/english/elaws_statutes_90h19_e.htm

O'Rourke, J. \& Houghton, S. (2009). The perceptions of secondary teachers and students about the implementation of an inclusive classroom model for students with mild disabilities. Australian Journal of Teacher Education, 34(1), 23-41.

Ostrosky, M. M., Laumann,, B. M., \& Hsieh, W. (2006). Early childhood teachers' beliefs and attitudes about inclusion: What does the research tell us? In B. Spodck \& O. N. Saracho (Eds.) Handbook of Research on the Education of Young Children (2nd ed.). Mahwah, NJ: Lawrence Eribaum Associations, Inc.

Perlman, M., Kankesan, T. \& Zhang, J. (2008). Promoting diversity in early childhood education. Early Child Development and Care, 1-33.

Pescsosolido, B.A., Jensen, P. S., Martin, J.K., Perry, B.L., Olafsdottir, S. \& Fettes, D. (2008). Public knowledge and assessment of child mental health problems: Findings from the 
national stigma study-children. Journal of the American Academy of Child * Adolescent Psychiatry, 47(3), 339-349.

Niemeyer, J. A. \& Proctor, R. (2001). The influence of experience on student teachers' beliefs about inclusion. Journal of Early Childhood Teacher Education, 23, 49-57.

Qu, S. Q. \& Dumay, J. (2011). The qualitative research interview. Qualitative Research in Accounting and Management, 8(3), 238-264.

Ramsey, P. G. (1995). Changing social dynamics in early childhood education. Child Development, 66, 764-773.

Richardson, V. (1996). The role of attitudes and beliefs in learning to teach. In J. Sikula (Ed.) Handbook of research on teacher education (pp.102-119). New York: Macmillan.

Rose, R. (2001). Primary school teacher perceptions of the conditions required to include pupils with special educational needs. Educational Review, 53(2), 147-156.

Sandall, S., McLean, M. E. \& Smith, B. J. (2000). DEC recommended practices in early intervention/early childhood special education. Missoula, MT: Division for Early Childhood (DEC)

Scruggs, T. E., \& Mastropieri, M.A. (1996). Teacher perceptions of mainstreaming inclusion, 1958-1995: A research synthesis. Exceptional children, 63, 59-74.

Shah, S. (2010). Canada's implementation of the right to education for students with disabilities. International Journal of Disability, Development and Education, 57(1), 5-20.

Shipley, T. (2002). Child care centers and children with special needs: Rights under the Americans with Disabilities Act and Section 504 of the Rehabilitation Act. Journal of Law \& Education, 31(3), 327-349 
Short, C. \& Martin, B. N. (2005). Case study: Attitudes of rural high school students and teachers regarding inclusion. The Rural Educator, 27(1), 1-10.

Sikes, P., Lawson, H., \& Parker, M. (2007). Voices on: Teachers and teaching assistants talk about inclusion. International Journal of Inclusive Education, 11(3), 355-370.

Skinner, D. \& Weisner, T.S. (2007). Sociocultural studies of families of children with intellectual disabilities. Mental Retardation and Developmental Disabilities Research Reviews, 13, 302-312.

Slee, R. (2001). Social justice and the changing directions in educational research: the case of inclusive education. International Journal of Inclusive Education, 5(2-3), 167-177.

Smith, M. K. \& Smith, K. E. (2000). "I believe in inclusion, but...": Regular education early childhood teachers' perceptions of successful inclusion. Journal of Research in Childhood Education, 14(2), 161-180.

Stoler, R. D. (1992). Perceptions of regular education teachers toward inclusion of all handicapped students in their classrooms. The Clearing House, 66(1), 60-62.

Terzi, L. (2004). The social model of disability: A philosophical critique. Journal of Applied Philosophy, 21(2), 141-157.

Thomas, G., Walker, D., \& Webb, J. (1998). The Making of the Inclusive School. London: Routledge.

Thornicroft, G. (2006). Shunned: Discrimination against people with mental illness. Oxford, UK: Oxford University Press.

Thornton, C. \& Underwood, K. (2012). Conceptualisations of disability and inclusion: Perspectives of educators of young children. Early Years, 1-15. 
Torrance, H. (2012). Triangulation, respondent validation, and democratic participation in mixed methods research. Journal of Mixed Methods Research, 6(2), 111-123.

Tourangeau, R., Rips, L., \& Rasinski, K. (2000). The Psychology of Survey Response.

Cambridge and New York: Cambridge University Press.

Underwood, K., \& Killoran, I. (2009). Early intervention practice and research in Ontario, Canada: Listening to the field. Journal of Early Childhood Teacher Education, 30, 298305.

Underwood, K., Valeo, A. \& Wood, R. (2012). Understanding Inclusive Early Childhood Education: A Capability Approach. Contemporary Issues in Early Childhood, 13(4), 290-299.

UNESCO. (1994). The Salamanca statement and framework for action on special needs education. Retrieved October 2, 2012 from http://www.unesco.org/education/pdf/SALAMA_E.PDF

UNESCO. (2005). Guidelines for Inclusion: Ensuring Access to Education for All. Retrieved from http://unesdoc.unesco.org/images/0014/001402/140224e.pdf

UNICEF. (2008). The child care transition: A league table of early childhood education and care in economically advanced countries. Retrieved from http://www.unicefirc.org/publications/pdf/rc8_eng.pdf

United Nations. (2006). Convention on the Rights of Persons with Disabilities. U.N. Doc. A/ 61/611. http://www.un.org/disabilities/convention/conventionfull.Shtml

Villeneuve, M., Chatenoud, C., Hutchinson, N. L., Minnes, P., Perry, A., Dionne, C., Frankel, E. B., Isaacs, B., Loh, A., Versnel, J., \& Weiss, J. (2013). Experiences of parents as their 
children with developmental disabilities transition from early intervention to kindergarten. Canadian Journal of Education, 36(1), 4-43.

Weller, D. R. \& McLeskey, J. (2000). Block scheduling and inclusion in a high school. Remedial and Special Education, 21(4), 209-218.

Winzer, M., \& Mazurek, K. (2011) Canadian teachers' associations and the inclusive movement for students with special needs. Canadian Journal of Educational Administration and Policy, 116, 1-24.

Woolfolk, A. (1998). Educational Psychology. (7th ed.). USA: Allyn and Bacon. 


\title{
Are you a Registered Early Childhood Educator?
}

\section{Have you worked with a child with special needs in your room?}

\section{We want to hear from you!!}

\author{
Talk to us about your perceptions of your training and support needs for inclusive \\ education.
}

What is the study about?

- Early childhood educators' perceptions of their own training and support needs.

- The study will aim to explore and provide insight on early childhood educators' perspectives of their training and support needs on inclusion.

\section{What do we want from you?}

- Participate in a one-on-one, open-ended interview about your experiences and perceptions of your own training and support needs.

- Complete a short self-efficacy and disability and education questionnaire.

- Participation will take about an hour of your time at the local library or at a location convenient to you.

This research study is an assignment towards the completion of the requirements for the Masters of Arts in Early Childhood Studies degree program at Ryerson University.

Your decision to take part in the study will not affect your relationship with the early childhood centre or Ryerson University

For more information, please contact:

Evelina Siwik, MA (cand.)

Early Childhood Studies, Ryerson University

esiwik@ryerson.ca 


\section{Appendix B - Informed Consent \\ Major Research Project \\ Ryerson University \\ Masters of Early Childhood Studies}

You are being asked to participate in a research study. Before you give your consent to be a volunteer, it is important that you read the following information and ask as many questions as necessary to be sure you understand what you will be asked to do.

\section{Title of Study}

ECEs' Training and Support Needs for Inclusive Education.

\section{Investigators}

Researcher: Evelina Siwik, M.A. (cand.) Early Childhood Studies, Ryerson University

Under the supervision of: Dr. Kathryn Underwood, Ph.D., Early Childhood Studies, Ryerson University

\section{Purpose of the Study}

This research is an assignment towards the completion of a major research project as part of the requirements for the Masters of Arts in Early Childhood Studies degree program at Ryerson University.

The purpose of the study is to gain insight into early childhood educators' perceptions towards their own training and support needs for inclusive education.

\section{Description of the Study}

Your perspectives on your training and support needs will be explored through an in-depth oneon-one interview which will take approximately one hour in length.

The interviewer will ask questions about the following concepts:

- Knowledge of and experience with children with disabilities

- Knowledge of and experience with inclusive education

- Description of your training for inclusive education

- Description of the support needs currently in place

In addition, you will be asked to complete two short questionnaires. One will be a self-efficacy scale measuring how you feel about your ability to do something; and the other will be disability and education questionnaire. 


\section{Risks or Discomforts}

It is possible that you may feel uncomfortable answering some of the questions or elaborating on any of the concepts established during the interview or in the questionnaire. In case that happens, you are free to refuse to answer any questions and/or stop the interview entirely at any time. You may also omit answering any questions on the questionnaire that you feel uncomfortable with. Additionally, you have the right to withdraw from the study altogether, and the observation notes that have been made before your withdrawal will be shredded, and will not be used for the purpose of the study. There will be no repercussions for dropping out and it will not affect your relationship with the early childhood centre or Ryerson University.

\section{Benefits}

The research findings will bring insight into the benefits and concerns of inclusive education from a early childhood educators' perspective. It will also add to the existing knowledge base about early childhood educator's beliefs about disability and inclusion. It cannot be guaranteed that you will receive any direct benefits from participating in this study. Your participation will provide insight into training and support needs, and in turn, aid in the recommendations for next steps to optimize the teaching of young children.

\section{Confidentiality}

No identifying information (names, centres, etc.) will be recorded, and pseudonyms will be used to ensure confidentiality. With your consent, interviews will be tape-recorded and transcribed, with no identifying information attached. Only the researcher and supervisor will have access to the recorded interviews, and they will be destroyed two years after study completion.

Transcriptions of the interviews will have no identifying information attached and will be stored on a password protected memory stick and computer.

\section{Incentives to Participate}

You will not be paid to participate in this study. The study is completely voluntary.

\section{Costs and/or Compensation for Participation}

The interviews will be held off premises at a convenient location for you, therefore the cost for the participant will be minimal.

\section{Voluntary Nature of Participation}

Participation in this study is voluntary. Your choice of whether or not to participate will not influence your future relations with Ryerson University or the childcare centre. If you decide to participate, you are free to withdraw your consent and to stop your participation at any time without penalty or loss of benefits to which you are allowed. At any particular point in the study, you may refuse to answer any particular question or stop participation altogether. 
Questions about the Study If you have any questions about the research now, please ask. If you have questions later about the research, you may contact:

\author{
Researcher: \\ Evelina Siwik \\ Graduate Student, Master of Arts \\ Ryerson University \\ esiwik@ ryerson.ca
}

\author{
Research Supervisor: \\ Dr. Kathryn Underwood \\ Associate Professor, \\ School of Early Childhood Studies \\ Ryerson University \\ kunderwood@ryerson.ca \\ (416) 979-5000, ext. 2519
}

If you have questions regarding your rights as a human subject and participant in this study, you may contact the Ryerson University Research Ethics Board for information.

Toni Fletcher, MA

Research Ethics Co-Ordinator

Office of Research Services

Ryerson University

(416)979-5000 ext. 7112

toni.fletcher@ryerson.ca

http://www.ryerson.ca/research

\section{$\underline{\text { Agreement }}$}

Your signature below indicates that you have read the information in this agreement and have had a chance to ask any questions you have about the study. Your signature also indicates that you agree to be in the study and have been told that you can change your mind and withdraw your consent to participate at any time. You have been given a copy of this agreement.

You have been told that by signing this consent agreement you are not giving up any of your legal rights.

Name of Participant (please print)

Signature of Participant

Date

Signature of Investigator

Date 


\section{Audiotape Recording Agreement}

Your signature below indicates that you are aware that this interview will be audio-recorded and verbatim transcriptions will be later made from the audio-recording. No identifying information will be attached to the recording.

Signature of Participant

Signature of Investigator
Date

Date 


\section{Appendix C - Interview Questions \\ Interview Questions for Frontline Staff}

\section{Demographic Questions}

Gender:

Number of years educating:

Number of centres taught at:

Age groups taught:

Age group currently teaching:

Education background (Degrees/Diplomas attained):

Please list any additional qualifications or other professional qualifications:

Please list any professional development activities taken in the last 3 years that are relevant to your work with students with learning disabilities:

\section{Interview Questions}

1. What is your experience with disability (professionally and/or personally):

2. How would you define inclusion?

3. What do you do to make your room inclusive for all children?

4. What is your role and responsibility in the Individual Program Plan (IPP) process? (probe: do you think you should have a role in the IPP process) 
5. What do you think are some of the biggest challenges with Individual Program Plans? (probe: how do you think you could support these needs?)

6. Do you think a room can be inclusive of all children? Explain. (probe: do you think there are certain disabilities that would not allow a child to participate?)

7. How do you assess the inclusiveness of your room? Can you give an example.

8. What do you see as the role of the Educational Assistant (or other professionals) in the classroom?

9. What resources contribute to the inclusiveness of a room?

10. What changes have you seen over the course of your ECE career?

11. How do you feel about the level and type of training that you have?

12. How do you feel about the level and type of resources that you have?

13. What training needs would you like to see to support inclusion?

14. What support needs would you like to see to support inclusion? 


\section{Interview Questions for Managers}

\section{Demographic Questions}

Gender:

Number of years in field:

Number of years as a Manager:

Number of centres taught at:

Age groups taught:

Education background (Degrees/Diplomas attained):

Please list any additional qualifications or other professional qualifications:

Please list any professional development activities taken in the last 3 years that are relevant to your role with children with learning disabilities:

\section{Interview Questions}

1. What is your experience with disability (professionally and/or personally):

2. How would you define inclusion?

3. What do you do to help ECEs make their rooms inclusive for all children?

4. What is your role and responsibility in the Individual Program Plan (IPP) process?

5. What do you think are some of the biggest challenges with Individual Program Plans? (probe: how do you think you could support these needs?) 
6. Do you think a centre can be inclusive of all children? Explain.

7. How do you assess the inclusiveness of your centre? Can you give an example.

8. What resources contribute to the inclusiveness of a centre? a room?

9. What changes have you seen over the course of your career?

10. What changes have you seen over the course of your role as a supervisor/manager?

11. How do you feel about the level and type of training that you have?

12. How do you feel about the level and type of resources that you have?

13. What training needs would you like to see to support inclusion?

14. What support needs would you like to see to support inclusion?

(probe with systemic support questions such as: what would you like to see more of from the government to help you become a more inclusive early childhood centre?) 


\section{Appendix D - Efficacy Scale}

For each statement below, select the response that best matches your level of agreement with that statement. Remember, all results are confidential, with only group responses being reported.

When a child does better than usual, many times it is because I exerted a little extra effort.

2 The hours in my room have little influence on children compared to the influence of their home environment.

3 The amount that a child can learn is primarily related to family background.

4 If children are not disciplined at home, they are not likely to accept any discipline.

5 When a child is having difficulty with an activity, I am usually able to adjust it to his/her level.

6 When a child does something better than he/she usually does, it is usually because I found better ways of modeling it for that child.

$7 \quad$ When I really try, I can get through to most difficult children.

8 An ECE is very limited in what he/she can achieve because children's home environment is a large influence on his/her achievement.

9 If a child masters a new concept quickly, this might be because I know the necessary steps in teaching that concept.

11 If a child did not remember information I gave in a previous activity, I would know how to increase his/her retention in the next activity.

12 If a child in my room becomes disruptive and noisy, I feel assured that I know some techniques to redirect him/her quickly.

13 The influence of a child's home experiences can be overcome by good teaching.

14 If one of the children could not do a class activity, I would be able to accurately assess whether the activity was at the correct level of difficultly.

15 Even an ECE with good teaching abilities may not reach many children.

$$
1
$$

$$
\begin{array}{lllll}
2 & 3 & 4 & 5 & 6
\end{array}
$$$$
\begin{array}{llllll}
1 & 2 & 3 & 4 & 5 & 6
\end{array}
$$$$
\begin{array}{llllll}
1 & 2 & 3 & 4 & 5 & 6
\end{array}
$$$$
\begin{array}{lllllll}
1 & 2 & 3 & 4 & 5 & 6
\end{array}
$$$$
\begin{array}{lllllll}
1 & 2 & 3 & 4 & 5 & 6
\end{array}
$$$$
\begin{array}{llllll}
1 & 2 & 3 & 5
\end{array}
$$$$
\begin{array}{llllll}
1 & 2 & 3 & 4 & 5 & 6
\end{array}
$$

$\begin{array}{llllll}1 & 2 & 3 & 4 & 5 & 6\end{array}$

$\begin{array}{lllllll}1 & 2 & 3 & 4 & 5 & 6\end{array}$

$\begin{array}{llllll}1 & 2 & 3 & 4 & 5 & 6\end{array}$

$\begin{array}{llllll}1 & 2 & 3 & 4 & 5 & 6\end{array}$

$\begin{array}{lllllll}1 & 2 & 3 & 4 & 5 & 6\end{array}$

$\begin{array}{llllll}1 & 2 & 3 & 4 & 5 & 6\end{array}$

$\begin{array}{llllll}1 & 2 & 3 & 4 & 5 & 6\end{array}$

\section{Thank you very much for your participation!}

Adapted from Teacher Questionnaire

October 8, 2003 


\section{Appendix E - Disability and Education Questionnaire}

For each statement below, select the response that best matches your level of agreement with that statement. Remember, all results are confidential, with only group responses being reported.

1. In general, do you think that people with disabilities receive equal opportunities in terms of education? (Yes/No/Don't know)

2. Do you agree or disagree that children with the following disabilities should attend the same centres as children without disabilities?

- Mental health difficulties (Strongly Agree/Agree/ Neither agree nor disagree/Disagree/Strongly disagree /Don't know)

- Intellectual or learning disabilities (Strongly Agree/Agree/ Neither agree nor disagree/Disagree/Strongly disagree /Don't know)

- Physical disabilities (Strongly Agree/Agree/ Neither agree nor disagree/Disagree/Strongly disagree /Don't know)

- Visual or hearing disabilities (Strongly Agree/Agree/ Neither agree nor disagree/Disagree/Strongly disagree /Don't know)

3. Do you have any children of your own with a disability? (Yes /(No/No children))

4. In general, would you object or not if children with the following disabilities were in the same class as your child?

- Mental health difficulties (Yes - I would object /No - I would not object /Don't know)

- Intellectual or learning disabilities (Yes - I would object /No - I would not object /Don't know)

- Physical disabilities (Yes - I would object /No - I would not object /Don't know)

- Visual or hearing disabilities (Yes - I would object /No - I would not object /Don't know)

\section{IF YES TO ANY PART OF Q4, PLEASE ANSWER THE FOLLOWING QUESTION:}

5. Why would you object if children with disabilities were in the same class as your child (children):

1. Special needs considerations e.g.

- Facilities in the study area, need special medication

- Require facilities, equipment to assist

- Require special care

2. Safety considerations e.g.

- Worries about infection

○ Worries about tendency towards aggression

- Possibilities of sudden relapse

3. Progress of children without disabilities hindered 
4. Progress of children with disabilities hindered

5. Appearance

6. Mobility Difficulties

7. Mental or Emotional Reasons e.g.

o Poor mental health

- Emotionally unstable

- More irritable

8. Other, please specify

National Disability Authority

2006 


\section{Appendix F - Participant Characteristics}

Table 1

Participant Characteristics

\begin{tabular}{cc}
\hline Category & $\mathbf{N}$ \\
\hline & $(\mathrm{n}=20)$
\end{tabular}

Gender

$\begin{array}{ll}\text { Female } & 18\end{array}$

Male 2

Years in the field

$\begin{array}{ll}0-5 \text { years } & 3 \\ 6-10 \text { years } & 4 \\ 11-20 \text { years } & 6 \\ 21+\text { years } & 7\end{array}$

Education

$\begin{array}{ll}\text { College Diploma } & 17\end{array}$

Bachelor Degree $\quad 6$

Masters Degree 1

Teachers College 1

Daycare Management Certificate 7

Additional Qualifications

Professional development or courses 13

relevant to working with children with

special needs in the last 3 years

Current Age Group

$(\mathrm{n}=15)$

Float

Toddler

4

Preschool

7

Kindergarten 2

School Age 1 